\title{
Molecular Mechanisms of Borrelia burgdorferi Phagocytosis and Intracellular Processing by Human Macrophages
}

\author{
Philipp Woitzik and Stefan Linder *(D) \\ Institute for Medical Microbiology, Virology and Hygiene, University Medical Center Eppendorf, \\ 20246 Hamburg, Germany; philipp.woitzik@stud.uke.uni-hamburg.de \\ * Correspondence: s.linder@uke.de
}

Citation: Woitzik, P.; Linder, S.

Molecular Mechanisms of Borrelia burgdorferi Phagocytosis and

Intracellular Processing by Human Macrophages. Biology 2021, 10, 567. https://doi.org/10.3390/

biology10070567

Academic Editors: Filippo Fratini and Giovanni Cilia

Received: 27 May 2021

Accepted: 20 June 2021

Published: 22 June 2021

Publisher's Note: MDPI stays neutral with regard to jurisdictional claims in published maps and institutional affiliations.

Copyright: (c) 2021 by the authors. Licensee MDPI, Basel, Switzerland. This article is an open access article distributed under the terms and conditions of the Creative Commons Attribution (CC BY) license (https:/ / creativecommons.org/licenses/by/ $4.0 /)$.
Simple Summary: Borreliae are a group of highly motile bacteria that are characterized by their corkscrew-like shape. They can be transferred by a tick bite to a human host and cause severe illnesses. Accordingly, an untreated infection with Borrelia burgdorferi can lead to the development of Lyme disease, which can affect the skin, joints, heart and nervous system. It is thus important to understand how borreliae interact with the human immune system, and which mechanisms lead to their depletion in the human body. Macrophages are part of the innate immune system and among the first cells that encounter invading borreliae. In this review, we discuss the molecular mechanisms that enable macrophages to recognize, take up and digest borreliae. We also point out potential ways in which borreliae might evade these mechanisms.

Abstract: Lyme disease is the most common vector-borne illness in North America and Europe. Its causative agents are spirochetes of the Borrelia burgdorferi sensu latu complex. Infection with borreliae can manifest in different tissues, most commonly in the skin and joints, but in severe cases also in the nervous systems and the heart. The immune response of the host is a crucial factor for preventing the development or progression of Lyme disease. Macrophages are part of the innate immune system and thus one of the first cells to encounter infecting borreliae. As professional phagocytes, they are capable of recognition, uptake, intracellular processing and final elimination of borreliae. This sequence of events involves the initial capture and internalization by actin-rich cellular protrusions, filopodia and coiling pseudopods. Uptake into phagosomes is followed by compaction of the elongated spirochetes and degradation in mature phagolysosomes. In this review, we discuss the current knowledge about the processes and molecular mechanisms involved in recognition, capturing, uptake and intracellular processing of Borrelia by human macrophages. Moreover, we highlight interactions between macrophages and other cells of the immune system during these processes and point out open questions in the intracellular processing of borreliae, which include potential escape strategies of Borrelia.

Keywords: Borrelia; coiling pseudopod; filopodia; Lyme disease; macrophages; phagosome; phagocytosis

\section{Introduction}

Lyme disease or Lyme borreliosis is a multisystemic bacterial infection, manifesting primarily in the skin, the nervous system and joints [1]. It is the most common vectorborne illness in North America and Europe [2]. Lyme disease was first described as an epidemic form of juvenile arthritis in Lyme, Connecticut in 1976 [3]. In 1982, Willy Burgdorfer identified a spirochetal bacterium isolated from ticks of the Ixodes family, and from patient samples, as the causative agent. The spirochete was accordingly called Borrelia burgdorferi [4]. Borreliae are morphologically characterized as irregularly coiled spirochetes that are 10-40 $\mu \mathrm{m}$ in length and up to $0.3 \mu \mathrm{m}$ in diameter [5]. They are highly motile, which is based on the presence of periplasmic flagella, and can reach velocities of up to $4.25 \mu \mathrm{m} / \mathrm{s}$ [6]. To date, 52 species of Borrelia have been identified, 21 of which 
are associated with Lyme disease [7]. Borreliae are mostly found in rodents and birds, and transmitted by tick bites, with infection of humans happening inadvertently [8]. In Europe and Asia, Borrelia afzelii, Borrelia garinii, Borrelia burgdorferi and Borrelia bavariensis are known to cause Lyme disease [9,10], while in North America, it is primarily caused by Borrelia burgdorferi [11]. New pathogenic strains are apparently emerging in Canada and the northern United States [12]. The group of Borrelia which cause Lyme disease is collectively referred to as the Borrelia burgdorferi sensu latu complex, whereas Borrelia burgdorferi as a species is addressed as Borrelia burgdorferi sensu stricto [10].

The course of Lyme disease can be divided into three distinct stages-the early localized infection, the early disseminated infection and late-stage Lyme disease- though the infection is not necessarily clinically apparent during all three stages [13]. In over $50 \%$ of cases, patients develop a painless skin rash called erythema migrans, which spreads in a characteristic ring-like morphology from the site of the tick bite 7-10 days after the infection [1]. Erythema migrans develops as a sign of the localized immune response and was shown to contain cells of the innate immune system, such as macrophages, neutrophils and dendritic cells [14]. Borrelia can enter the vasculature during the tick-bite and escape from the vascular system in a multi-step process comprising tethering, dragging, stationary adhesion and extravasation, leading to the distribution of the pathogen throughout the body [15]. Depending on the genospecies of the infections, roughly $5-60 \%$ of untreated erythema migrans progress into systemic infections, which can be divided into early disseminated infections and late-stage Lyme disease, according to the duration of symptom persistence $[1,13]$. Of note, $\sim 50 \%$ of patients in the disseminated stages of the infection report no prior erythema migrans [1]. Common manifestations include arthritis, carditis and neuroborreliosis, with variations in frequency depending on the underlying genotype of the infection [13]. In some cases, subjective symptoms such as fatigue, cognitive difficulties, myalgia and arthralgia persist for a significant period of time even after antibiotic treatment. The underlying etiology of the so-called post(treatment)-Lyme disease syndrome is not fully understood. Possible explanations range from microbial persistence or immune dysregulation to altered neural networks [16,17].

The immune response of the host is an important factor for preventing development or progression of Lyme disease. Of note, skin biopsies from erythema migrans are enriched in macrophages, neutrophils and dendritic cells [14]. These cells are part of the innate immune system and are thus the first line of defense against the infection. Here, we focus on the role of macrophages in the elimination and potential persistence of Borrelia in the human host.

To successfully eliminate borreliae, macrophages have to perform a series of finely tuned processes (Figure 1). At first, the immune cells need to recognize, capture and immobilize the highly motile Borrelia cells [18]. To achieve this, macrophages initially form rigid actin-rich protrusions called filopodia that contain closely-bundled, unbranched actin filaments $[19,20]$. Subsequently, a more flexible actin-rich structure, the coiling pseudopod, wraps around the captured bacteria and pulls them into the phagosome, a special compartment derived from the cell membrane. The early phagosome then matures progressively into the late phagosome and the phagolysosome. This process is accompanied by the compaction of the elongated spirochete [21], by progressive acidification of the compartment and the acquisition of lytic enzymes. These steps and the respective molecular mechanisms will be discussed in the following section. Please note that the term "Borrelia" in this review refers to members of the Borrelia burgdorferi sensu latu complex, especially in the context of Lyme disease, and not to other species such as B. recurrentis or B. miyamotoi that cause other infectious diseases. It is likely that several of the described mechanisms also apply to these other Borrelia species, but this has not been formally proven yet. 


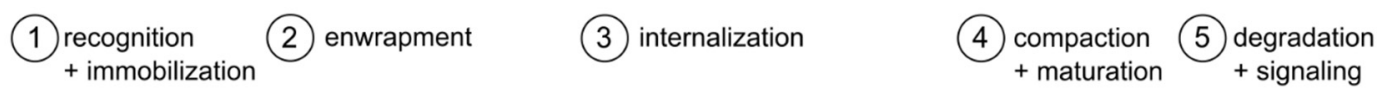

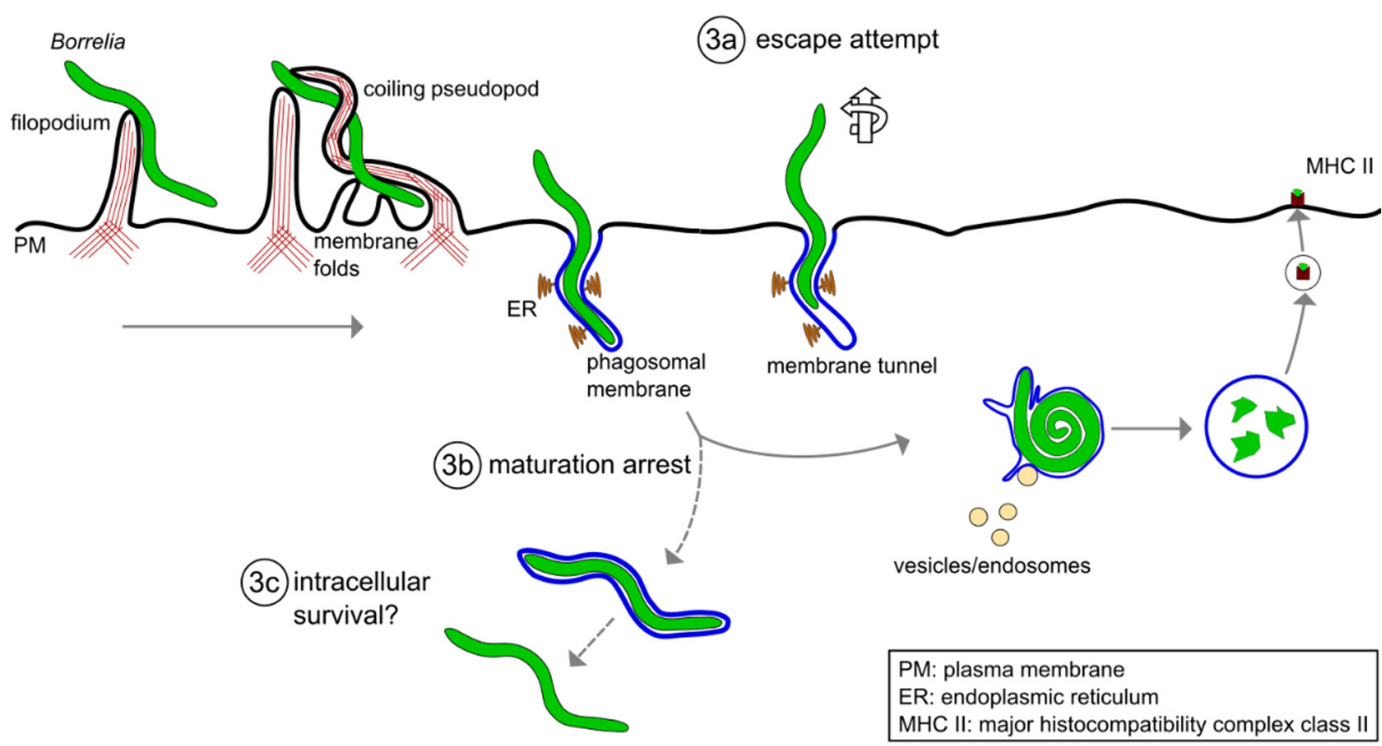

Figure 1. A model of the phagocytic uptake and intracellular processing of Borrelia by macrophages. $(\mathbf{1}, \mathbf{2})$ Actin-rich uptake structures. (1) Filopodia immobilize motile Borrelia at the host cell surface, with (2) subsequent enwrapment by a coiling pseudopod. (3) Borreliae are taken up into a plasma membrane-derived compartment, the phagosome. The phagosomal membrane loosely follows the spirochete morphology and contacts the endoplasmic reticulum (ER) at multiple sites. (3a-3c) Potential deviations from the regular pathway of internalization and processing. (3a) A subset of borreliae partially extract themselves from the nascent phagosome, resulting in the formation of membrane tunnels. (3b) A subpopulation of borreliae lose the phagosomal membrane and retain their elongated morphology, (3c) leading to increased survival in the host cell. (4) The elongated spirochete is compacted into a globular structure within the phagosome. This is initiated by contact with endocytic vesicles, which leads to local membrane tubulation and thus shrinkage of the phagosomal surface. (5) Borreliae are degraded within mature phagolysosomes. Subsequently, complexes consisting of MHCII and pathogen-derived peptides are exposed on the cell surface for antigen presentation.

\section{Phagocytic Uptake of Borrelia burgdorferi by Macrophages}

Phagocytosis is defined as a multi-step process comprising recognition and capture of a particle larger than $0.5 \mu \mathrm{m}$ in diameter, its internalization and its subsequent degradation [22]. It is an important factor in host defense against infection and a significant part of the immune (and inflammatory) response [23,24]. In mammals, some cells, including macrophages, dendritic cells, osteoclasts and eosinophils, show high phagocytic activity and efficiency and are therefore called "professional phagocytes" [25,26].

Phagocytes can recognize Borrelia through a set of receptors, including the Fc $\gamma$-receptor $\left(\mathrm{F}_{\mathrm{c}} \gamma \mathrm{R}\right)$, which recognizes opsonized borreliae through the constant fraction of bound immunoglobulins [27-30], and the complement receptor-3, which facilitates uptake through recognition of two of the major lipoprotein components of the spirochete's cell membrane, outer surface proteins A and B (OspA and OspB), in an iC3b-independent manner [31-33]. Detection of other spirochetal lipoproteins or pathogen associated molecular patterns (PAMPs) through pattern recognition receptors such as Toll-like receptors 2 (TLR2) and 3 (TLR3) has also been shown to be part of the recognition [34-37]. The downstream signaling of TLR2 and TLR3 proceeds through myeloid differentiation factor 88 (MyD88)dependent and MyD88-independent pathways, involving, among others, phosphoinositide 3-kinase (PI3K), an important trigger of actin polymerization [37,38]. Deficiency in TLR2, CR3 or Fc $\gamma R$ leads to increased severity of symptoms and decreased numbers of neutralized Borrelia [39-41]. Of note, macrophages can adhere to both opsonized and non-opsonized Borrelia, but opsonization of the bacteria through Borrelia-specific antibodies or through 
serum, which contains factors of the complement system, has been shown to increase adhesion rates by a factor of 4-5 [42]. A series of other receptors has been detected by mass spectrometry in Borrelia-containing phagosomes, and shRNA-mediated depletion showed that some of them, including PLAUR (uPAR), CLEC13A, CLEC4N (Dectin 2), CLEC4B1, MARCO, STABILIN2 and CD33, are important for phagocytic uptake, whereas others, such as LY6E, CD59A, CD24A, CLEC4D, CLEC10A, STABILIN1, MSR1 and SIGLEC5, seem to negatively regulate phagocytosis [30]. Collectively, this evidence suggests that multiple receptors and signaling pathways act synergistically to facilitate efficient recognition and uptake of Borrelia by immune cells.

To increase their chances of encountering a pathogen, activated macrophages probe their environment by using actin-based cell protrusions called filopodia that are also enriched in receptor proteins (Figure 2) [43]. Co-incubation of primary human macrophages with live or heat-killed Borrelia burgdorferi greatly increased the number and the length of filopodia per cell, whereas incubation with supernatant from Borrelia cultures did not induce any noticeable changes, indicating that this process is actively driven by the macrophage upon encountering the spirochete [20]. Filopodia are elongated, finger-like structures that contain bundles of F-actin and undergo constant extension and retraction [43-45], based on actin polymerization dynamics. Consequently, members of the formin family, which are regulators of linear actin filaments, have been shown to be crucial for these processes. Formins are involved in the elongation, nucleation, bundling and severing of actin filaments, and the actual activity is dependent on the specific isoform [46]. For filopodia formation in macrophages, three formins are of major importance: mDia1, FMNL1 and Daam1. mDia1 localizes at the tip of the protrusion and is correspondingly important for actin filament elongation [20,47]. FMNL1, localized both at the tip and the shaft of filopodia, exhibits actin severing activity that creates barbed ends, which supports the growth of new filaments [20,48]; and Daam1, which is enriched at the shaft, is involved in actin bundling, thereby contributing to the stability of the protrusion $[19,20]$. In addition, fascin, another actin bundling protein, is also located along the shaft of the filopodia [19]. SiRNA-mediated depletion of either of these proteins led to significant decreases in the number of filopodia contacting Borrelia and in the uptake of Borrelia into macrophages [19,20]. Generally, a basal branched actin-network created by Arp2/3 [49] is required as the foundation for a subset of filopodia [50], although its specific requirement for the formation of Borreliainduced filopodia has not been evaluated so far. To prevent the encountered pathogen from escaping, filopodia are able to pull it towards the cell surface or at least immobilize it [43,51-53], which is especially important when macrophages are confronted with highly motile pathogens, such as Borrelia. Inhibition of actin turnover using jasplakinolide led to a loss of this ability to exert a force on the captured pathogen [43].

Subsequent to capture by filopodia, borreliae are internalized by the formation of uptake structures that are also based on actin dynamics. For macrophages, two modes of internalization have been demonstrated: (1) Conventional phagocytosis, a process in which multiple cell protrusions form symmetrically around the attached pathogen and enwrap it. (2) A specialized process called coiling phagocytosis [54,55], which seems to be the predominant pathway for Borrelia uptake [54]. In this process, a single major actin-rich protrusion extends along the spirochete, closely following its helical morphology, and wraps itself multiple times around the elongated pathogen (Figure 2). Novel data suggest that in addition to the predominant coiling pseudopod, multiple small membrane folds support this process by attaching themselves to the pathogen at several places along its length [56]. Similarly to immobilization by filopodia, this process is actively driven by the host cell, as both live and heat- or chemically-killed Borrelia were observed to be taken up by this process. In contrast, neither supernatant from bacterial culture nor fragmented bacteria induced uptake by coiling phagocytosis, suggesting that this uptake mechanism is a specific response to the elongated helical morphology of the spirochete [57]. Interestingly, formation of these pseudopodia is linked to Daam1, one of the formins also responsible for the formation of filopodia, [19], which makes Daam1 the only actin regulator with demonstrated activity at 
both actin-based uptake structures for borreliae so far. In addition to Daam1, which is localized along the entire length of the pseudopod, the Arp2 3 complex is found in the form of dot-like accumulations at the turning points of the coiling pseudopod [18,42]. As Arp2/3 creates branched actin networks [49], the current hypothesis is that these Arp2/3-based spots could create "hinges" along the pseudopod, which, in combination with the more rigid, unbranched actin bundles created by Daam1, confer the necessary flexibility for the formation of the helical pseudopod [18]. The small GTPases CDC42 and Rac1, members of the Rho family, are upstream regulators of Arp2/3. Consistently, inhibition of CDC42 and Rac1 via microinjection of constitutively inactive mutants or C3-transferase, a Rho inhibitor, led to decreased formation of coiling pseudopods [42]. In addition, this pathway involves activation of the Arp2/3 complex by the nucleation-promoting factor WASP (WiskottAldrich syndrome protein) [42,58]. As previously mentioned, downstream signaling of TLR2 and TLR3 involves MyD88-dependent and independent pathways. Recent data from MyD88-deficient murine bone-marrow derived macrophages (BMDMs) showed no change in adhesion to Borrelia and no deficiency in phagosomal degradation, but reduced uptake of borreliae. Furthermore, MyD88-signaling upregulates the expression of Daam1, Rac1, CDC42 and Akt1. Collectively, these data suggest a prominent role for MyD88 in regulating the formation of coiling pseudopods [37].

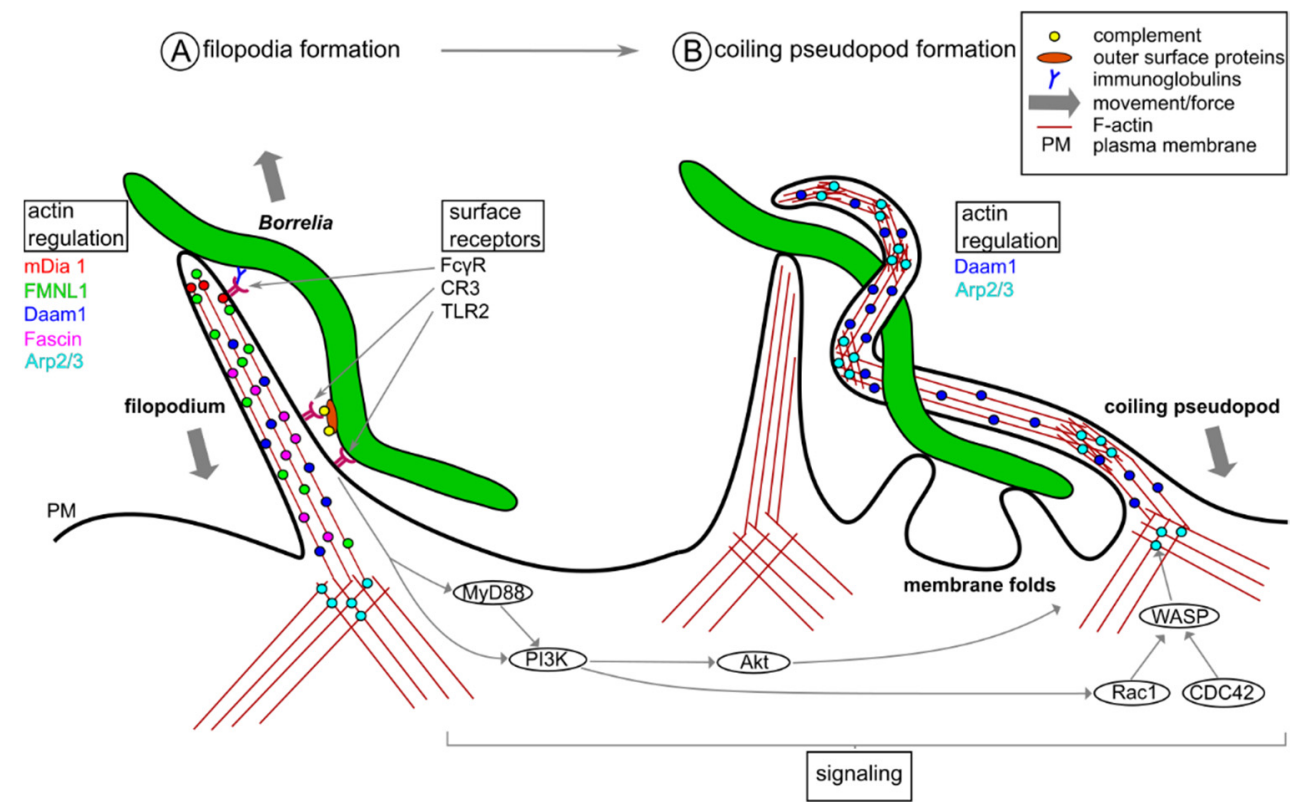

Figure 2. Actin-rich uptake structures during Borrelia phagocytosis. (A) A filopodium enriched in surface receptors recognizes and attaches to the Borrelia cell. The formin mDia1 localizes at the tip of the protrusion, where it regulates actin filament elongation. Two other formins, FMNL1 and Daam1, along with the actin bundling protein fascin, are located along the shaft of the filopodium, and regulate the formation and architecture of unbranched actin filaments. The Arp2/3 complex is found in the underlying branched actin network. The filopodium likely exerts a force to counter movement of the spirochete. (B) A second actin-rich structure, the coiling pseudopod, wraps itself around the spirochete, leading to internalization. The Arp2/3 complex is located at the turning points of the pseudopod, likely creating "hinges" of branched F-actin, which alternate with unbranched actin filaments regulated by Daam1. Arp2/3 is activated by a pathway involving Rac1, CDC42 and WASP. Moreover, TLR2-receptor signals in MyD88-dependent and MyD88-independent pathways involving PI3K and Akt, leading to recruitment of Arp2/3, thereby promoting formation of the coiling pseudopod.

Following enwrapment by the coiling pseudopod, the entire phagocytic complex consisting of the pathogen and the pseudopod is internalized by a series of fusion events between adjacent membrane parts, thereby creating an enclosed compartment which sub- 
sequently pinches off from the plasma membrane [54]. Of note, owing to the pronounced length of the spirochete, internalization can already begin while substantial parts of the bacterium are still extracellular. It may thus take longer than $40 \mathrm{~min}$ for a single spirochete to be completely internalized [18].

\section{Intracellular Processing of Borrelia burgdorferi in Macrophages}

As mentioned, intracellular processing of a Borrelia cell can start even before it is internalized in its entirety [21,56]. Generally, internalized bacteria are taken up into a phagosome, which constitutes a plasma membrane-derived compartment that is initially filled with fluids from the extracellular space [59]. In the case of Borrelia internalization, nascent phagosomes are still accessible from the extracellular space. Of note, in nascent phagosomes, the phagosomal membrane only loosely follows the form of the spirochete, resulting in infrequent points of contact between the membrane and the pathogen [56]. Collectively, these areas of close contact form an ever-increasing barrier to the extracellular space. In consequence, Borrelia-specific antibodies could only reach proximal areas within the phagosome [56], although experiments using the cell surface markers concavalin Agold, ruthenium red and tannic acid showed that the internal membranes of the nascent phagosomes could be stained up to the time of complete enclosure of the spirochete, indicating that fluids and small solutes could still access the entire length of the unclosed phagosome [54].

In approximately $2-5 \%$ of the cases, the phagosomal membrane enwrapping the internalized part of the spirochete was shown to extend into the host cytoplasm beyond the tip of the pathogen for more than $10 \mu \mathrm{m}$. These structures, called tunnels, might point to partial escape of the highly motile Borrelia from the unclosed phagosome (Figure 1). In macrophages transfected with RFP-LactC2, a reporter of phosphatidylserine and therefore the outsides of early phagosomes, the signal confirmed that these tunnels are indeed part of the phagosome and are derived from the plasma membrane [56]. Collectively, this demonstrates that uptake of Borrelia by macrophages is not a simple, one-directional process but rather an active "tug-of-war" between highly motile borreliae and the phagocyte.

\subsection{Compaction of Borrelia in the Phagosome}

An early step during the intracellular processing of Borrelia is the compaction of the elongated spirochete into a globular form, which is associated with a reduction in phagosomal surface (Figure 3) [21]. This reduction of the membrane surface area is likely due to the extrusion of membrane tubules, which could be observed frequently, especially at sites of curvature discontinuity [21,56]. Multiple proteins have been identified which play crucial roles in the regulation of this process, including RabGTPases, sorting nexin 3 (SNX3) and galectin-9 [60]. RabGTPases are regulators of vesicle trafficking and vesicle fusion with and fission from membranes [61]; sorting nexins are a family of proteins involved in intracellular trafficking and possess a phospholipid binding PX domain [62]; the galectin family is involved in carbohydrate binding on the cell surface, but also in the regulation of intracellular trafficking pathways [63].

Initially, Borrelia are internalized in a Rab22a-positive phagosome, which is in turn fused with vesicles that are positive for both Rab5a and SNX3 (Figure 3). siRNA-mediated depletion of either of those proteins significantly decreased the proportion of compacted Borrelia $[21,60]$. Interestingly, these points of contact between phagosome and vesicles are especially found at sites of altered membrane curvature on the phagosomal membrane, which also constitute the sites of membrane tubule formation and abscission $[18,21,60]$. It has been shown that Rab5a vesicles contact the phagosomal coat through binding of vesicle-localized SNX3 with the phagosomal phospholipid PI(3)P (Phosphatidylinositol 3-phosphate) [60]. In particular, a SNX3 construct carrying a point mutation in the PX domain and thus being unable to bind $\mathrm{PI}(3) \mathrm{P}$, was unable to rescue compaction in SNX3depleted macrophages, and inhibition of PI(3)P formation using the PI3K class III inhibitor wortmannin significantly decreased compaction rates as well. Collectively, these data 
lead to the conclusion that the interaction between SNX3 and PI(3)P is necessary for the compaction of Borrelia within phagosomes [60]. Interestingly, PI3 kinase (PI3K), one of the enzymes able to generate PI(3)P, has been shown to be particularly active at sites of altered membrane curvature [64], and such sites are a natural consequence of the helical spirochete morphology. Of note, PI(3)P was shown to be gradually enriched at the phagosome. This enrichment was accompanied by only occasional contact with PI(3)P-positive endocytic vesicles, suggesting local generation of the phospholipid at the phagosome surface, with an only accessory influx of vesicle-delivered PI(3)P [60].

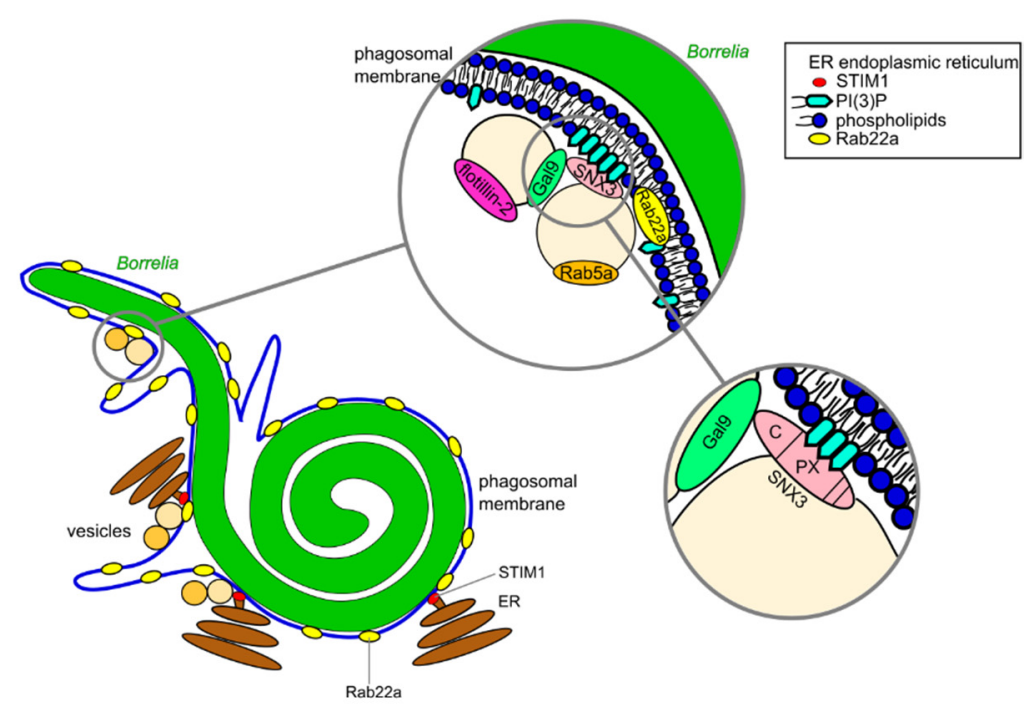

Figure 3. A model of Borrelia compaction within the phagosome. The phagosomal membrane is enriched in Rab22a and is met by ER-tethered vesicles positive for both Rab5a and SNX3. Vesicle contact takes place preferentially at sides of altered membrane curvature, owing to the relative enrichment of the phospholipid PI(3)P. The PX domain of SNX3 binds PI(3)P, leading to the docking of Rab5a vesicles, while the SNX3 C-terminus binds galectin-9, resulting in recruitment of a second distinct vesicle population that is positive for flotillin-2. Contact with both vesicle populations is important for the local initiation of membrane tubules, which lead to a reduction of the phagosome's surface and thus to spirochete compaction.

It is thus likely that the helical shape of Borrelia and the resulting phagosome morphology lead to increased PI3K activity at helical turns, thereby generating docking sites for Rab5a vesicles through a SNX3-PI(3)P interaction [60]. Moreover, SNX3 does not only act as an adaptor for Rab5a vesicles, as it also binds galectin-9. Consistently, a SNX3 construct lacking its C-terminal region, an 11 amino acid residue stretch identified to be responsible for the interaction with galectin-9, failed to rescue regular levels of compaction in SNX3 knockdown cells. Interestingly, galectin-9 is present at a vesicle population that is also positive for flotillin-2 [60], a protein implicated in trafficking, signal transduction and endocytosis [65]. Furthermore, this vesicle population is distinct from the SNX3/Rab5a vesicle population, and is only recruited to borreliae phagosomes after SNX3/Rab5a vesicle docking. However, siRNA-mediated depletion of galectin-9 leads to a comparable reduction in phagosomal compaction. Depletion of both galectin-9 and SNX3 simultaneously did not result in additive effects, indicating that both proteins act in the same pathway that regulates compaction of the Borrelia-containing phagosome $[21,60]$. Interestingly, macrophages depleted in Rab22a, Rab5a, SNX3 or galectin-9, either singly or in combination, were still able to maintain $\sim 50 \%$ of regular phagosome compaction levels, hinting at the existence of one or more alternative pathways for this process $[21,60]$.

Importantly, in addition to the phagosome and its associated vesicle populations, the endoplasmic reticulum (ER) has emerged as a major regulator of Borrelia intracellular processing. Multiple ER tubules were observed in close proximity to phagosomes [21] 
which were nascent, incompletely closed or in the process of compaction (Figure 3) [56]. Recent data also demonstrated the presence of multiple bona fide ER contact sites at Borrelia-containing phagosomes that were positive for the marker STIM1 [56]. Moreover, SNX3/Rab5a vesicles have been shown to be tethered to the ER [21,56], comparably to what was previously shown for endosome-ER interactions [66]. It is thus very likely that ER contacts with vesicles and phagosomes play both structural and functional roles in the maturation process of the Borrelia-containing phagosome, which will also be discussed in the next section.

\subsection{Phagosomal Maturation and Development of the Phagolysosome}

Generally, the early phagosome is still filled with fluid derived from the extracellular space and does not show any bactericidal activity. Shortly after the separation from the cell membrane and the sealing of the phagosome, further maturation begins and endocytic vesicles fuse with the phagosome, drastically changing the composition of its contents, leading to acidification and the acquisition of enzymes necessary for the degradation of the pathogen. This new hybrid organelle is called the phagolysosome [59,67]. As discussed, phagosomal compaction of initially elongated Borrelia cells seems to be an important step in the maturation of the phagosome, as depletion of many of the regulators involved in this step also results in defects in the further maturation process.

RabGTPases, a family of intracellular trafficking regulators [61], are involved in both steps of borreliae intracellular processing. Generally, individual Rab family members show distinct localizations within the cell, often in specific membranes or compartments, such as the phagosome. They are involved in regulating the compositions of these membranes; in the movement of organelles by regulating the interactions with elements of the cytoskeleton [68]; in membrane fusion and fission events; and in the trafficking of vesicles [61]. As discussed above, Rab22a was found to be enriched at the coat around the early Borrelia-containing phagosome; vesicles positive for Rab5a contact the Rab22a coat especially at sites of altered membrane curvature (Figure 4) [21]. Both proteins play an important role in the compaction of the elongated phagosome into a globular structure, but also in the maturation of the phagosome into an organelle capable of degrading the pathogen, as siRNA-mediated knockdown of either protein led to a significant decrease in proteolytic activity of Borrelia-containing phagosomes, as determined by reduced fluorescence of DQ-BSA (dequenched bovine serum albumin), a reporter of proteolysis. Consequently, internalized borreliae show higher survival rates in cells depleted in Rab22a or Rab5a [21,60].

How can the molecular interplay between Rab5a and Rab22a in borreliae phagosome maturation be envisioned? Generally, Rab5 and its effector EEA1 (early endosomal antigen 1) have been described as important regulators for the trafficking of early endosomes [69], and another RabGTPase, Rab7, was found to be crucial for the development of the late endosome and endosomal degradation [70]. Rab5a and Rab7 have also been observed in early and late phagosomes, respectively. As phagosomes are known to interact with the endocytic pathway, it seems likely that they play similar roles in phagosome maturation $[59,67,71]$. For other pathogens, especially Mycobacteria, a crucial role for Rab22a was found in the conversion from Rab5-positive to Rab7-positive phagosomes, and a lack of this conversion led to an arrest of phagosome maturation [71]. Considering the detection of Rab7 in Borrelia-containing phagosomes and also the impaired degradation of Borrelia in Rab22a-deficient macrophages [21], a similar role for Rab22a in the conversion from Rab5a-positive to Rab7-positive phagosomes could be possible. Moreover, the involvement of other Rab proteins is also likely, as several Rabs have been linked to phagosome maturation [72] and have also been detected at Borrelia phagosomes [21], although their potential impact on maturation of Borrelia-containing phagosomes is currently unclear. This should be fertile ground for future research. 


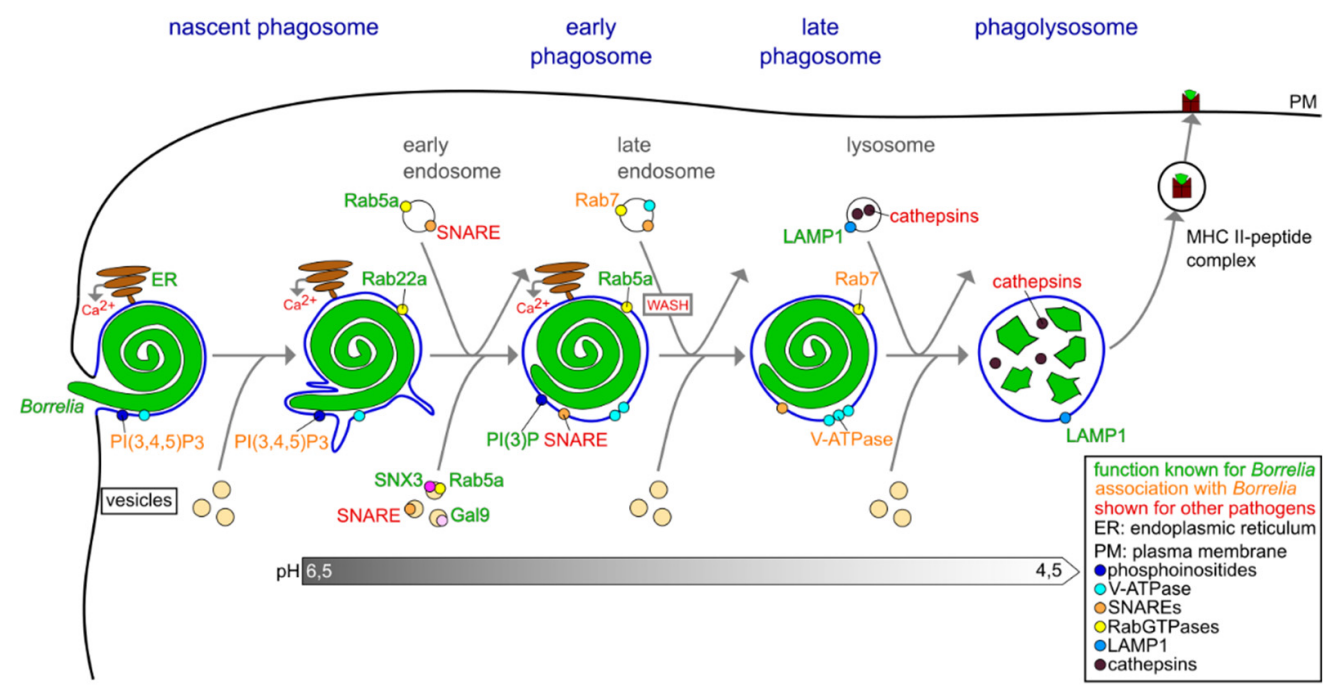

Figure 4. The maturation of Borrelia-containing phagosomes. The nascent phagosome makes contact with the ER and is subsequently pinched off from the plasma membrane. During its maturation into a phagolysosome, the compartment comes into contact with different subpopulations of vesicles, which regulate compaction and acidification. This is accompanied by changes in the composition of the phagosomal membrane and also by respective enrichments of different RabGTPases during specific stages. Molecular regulators with documented roles in Borrelia phagosome maturation are shown in green, while those that have only been detected, but have unknown roles, are shown in orange. Central regulators of phagosome maturation for other pathogens, with likely but still unproven roles in borreliae phagosome processing, are shown in red.

The acquisition of endosomal enzymes by phagosomes is thought to happen through a series of transient contacts with endosomal compartments in a "kiss-and-run" fashion (Figure 4) [73]. These fusion events between the respective stages of phagosomes and endosomes are facilitated by the RabGTPases that are predominant in both compartments at these stages $[73,74]$. This general concept likely also applies for Borrelia phagosome maturation, as both Rab5a/SNX3-positive and galectin-9-positive vesicles were observed to repeatedly contact borreliae-containing phagosomes, but not fuse with them [21,60]. Generally, in addition to RabGTPases, a role for SNAREs (soluble N-Ethylmaleimidesensitive factor-attachment protein receptors), and their binding partners, SNAPs (NSFattachment proteins), has been shown for the targeting of vesicles in the endosomal and phagosomal progression $[59,75]$. However, data specifically for borreliae phagosomes are currently lacking. A direct interaction between EEA1, a downstream effector of Rab5, and syntaxin 13, a SNARE protein, has been described to be necessary for early membrane fusion events in a cell-free system of endosome fusion [76,77]. It is thus possible that, in addition to the previously identified Rab proteins, SNARE complexes could be involved in the regulation of these interactions between the endosomal and phagosomal pathways in Borrelia phagosome progression.

WASH (Wiskott-Aldrich syndrome protein and SCAR homologue) is a known regulator of the Arp2/3 complex and thus of actin polymerization [78]. In Dictyostelium, a eukaryotic bacterivore, loss of WASH did not alter the rate of phagocytosis of latex beads, but led to reduced proteolysis within the phagosomes and reduced acquisition of lysosomal enzymes [79]. As phagocytosis is a highly conserved process between lower and higher eukaryotic cells [80] and fusion events between late endosomes and latex bead-containing phagosomes depend on F-actin polymerization [81], a role of WASH in the interaction between the phagocytic and endocytic pathway during Borrelia processing seems possible.

During the process of maturation, phagosomes generally establish progressively more acidic conditions inside, a step thought to be necessary for the bactericidal ability, as (1) most lysosomal enzymes prefer these acidic conditions, (2) the low $\mathrm{pH}$ supports denaturation and (3) the creation of reactive oxygen species requires protons $[59,82,83]$. 
These protons are actively transported into the phagosome by the vacuolar-type proton transporting ATPase (V-ATPase) [59], which is in general recruited in the early stages of the phagosome and colocalizes with Rab7, a marker progressively enriched during the maturation of endosomes and phagosomes [82,83]. In murine macrophages, depletion of the V-ATPase disrupted acidification of latex bead-containing phagosomes and impaired the bactericidal ability of $E$. coli phagosomes, yet the recruitment of lysosomal enzymes was unhindered [84]. Indeed, inhibition of the V-ATPase using the inhibitor bafilomycin also resulted in a loss of acidification of Borrelia-containing phagosomes [21], pointing to the significance of this enzyme in the context of intracellular degradation of Borrelia by macrophages (Figure 4).

Hydrolases constitute another group of enzymes that are usually acquired by phagosomes through the mentioned fusion events with lysosomes. More than 50 hydrolases have been identified within lysosomes, comprising mostly cysteine, aspartic and serine proteases that are predominantly members of the cathepsin family [85]. Initial data showed colocalization between cathepsin L and Borrelia-containing phagosomes in murine macrophages [86]. However, it is not yet known which hydrolases are indeed required for proteolytic processing of Borrelia in phagolysosomes. In addition, the phagosomal membrane acquires LAMPs (lysosome-associated membrane glycoproteins) during the maturation process. The function of these proteins are unknown, but they have been hypothesized to be involved in the protection of the phagosomal membrane from hydrolysis through the contained proteases [85] and in the later stages of endosomal maturation [87]. They are used as markers for late endosomes and phagosomes, and LAMP1 has been observed specifically at Borrelia-containing phagosomes (Figure 4) [21].

A close spatial localization between Borrelia-containing phagosomes and the endoplasmic reticulum (ER) has been observed during the early stages of the phagosomal maturation process $[21,56]$. Indeed, stromal interaction molecule 1 (STIM1), a transmembrane component of ER contact sites [88], has been detected at these sites, pointing to the existence of bona fide ER contact sites at Borrelia phagosomes [56]. Membrane contact sites (MCS) between the ER and other organelles and structures moved into the focus of ER-related research in recent years. In general, functions ascribed to these MCS include localized calcium signaling, lipid transfer and involvement in membrane trafficking [89]. The specific role of MCS in the processing of Borrelia is still unknown. Indeed, MCS at phagosomes have only been described in a limited number of cases [90], which is in contrast to their well-documented role on endosomes [66,91]. Still, several possible functions could be envisioned-most notably, localized calcium signaling. Interestingly, $\mathrm{Ca}^{2+}$ levels are increased following activation of $\mathrm{Fc} \gamma \mathrm{R}$ or $\mathrm{CR} 3$, both of which are also involved in recognition of Borrelia. Furthermore, STIM1 is involved in the pathways during ER-dependent $\mathrm{Ca}^{2+}$ signaling [92]. In addition, a role for $\mathrm{Ca}^{2+}$-signaling has been reported for the processing of other pathogens in macrophages. Notably, Mycobacterium tuberculosis was shown to escape degradation by preventing elevation of $\mathrm{Ca}^{2+}$ levels, resulting in defects in acidification and the acquisition of lysosomal enzymes [93]. Further data suggest a role for $\mathrm{Ca}^{2+}$ in the regulation of the fusion between phagosomes and lysosomes in a cell-free assay [94]. Collectively, many proteins associated with Borrelia phagocytosis are known to be involved in ER-dependent calcium signaling, pointing to possible but currently unproven roles in Borrelia intracellular processing.

In addition to regulatory and effector proteins, specific lipids also play important roles in intracellular trafficking and processing of pathogens. For Fc $\gamma$ R-mediated phagocytosis of sheep red blood cells (SRBCs) and polysterol beads by RAW 264.7 macrophages, accumulation of $\mathrm{PI}(3,4,5) \mathrm{P}_{3}$ in the phagosomal cup has been observed [95]. Moreover, inhibition $\mathrm{PI}(3,4,5) \mathrm{P}_{3}$ formation by targeting $\mathrm{PI}(3)$-kinase class I led to defects in the uptake of SRBCs and latex beads, but did not influence phagosome maturation [96]. Indeed, Borreliacontaining phagosomes were also shown to be associated with $\mathrm{PI}(3,4) \mathrm{P}_{2}$ or $\mathrm{PI}(3,4,5) \mathrm{P}_{3}[60]$, yet the potential impact of these phospholipids on Borrelia phagosome maturation is unclear. In contrast, a clear role has been described for PI(3)P, which was found to become 
progressively enriched in the membrane of the early phagosome in general [59] and also specifically for Borrelia (Figure 4) [60]. As mentioned, it plays an important role in the process of borreliae compaction and recruits Rab5a-/SNX3-positive vesicles to the phagosome by interacting with the PX domain of SNX3 [60]. In line with these findings, pharmacological inhibition of PI(3)P-generating PI(3)-kinase class III by wortmannin disrupted the maturation of latex bead-containing phagosomes in RAW 264.7 macrophages [59,96]. A similar effect for Borrelia-containing phagosomes could be envisioned, as Rab5a and SNX3, both present at the vesicles interacting with $\mathrm{PI}(3) \mathrm{P}$, were shown to be important for the proteolytic degradation in phagosomes [21,60]. As ER membrane contact sides (MCS) have been described to play a role in lipid transfer, and the composition of the phagosomal membrane changes during development of the phagosome [97], it is conceivable that the mentioned ER-phagosome contacts are also involved in this process.

One of the latest steps in the phagocytic process is the presentation of pathogenderived peptides in an MHC class II-peptide complex. These complexes are formed within the phagosome and travel from the phagosome back to the cell surface, a process necessary for antigen presentation to other immune cells, and particularly for a targeted T-cell response [98]. Accordingly, upregulation of MHC II has been observed in murine macrophages challenged with Borrelia in vivo and during subsequent proliferation of Borrelia-reactive T-cells [99]. In contrast, recent data suggest that Borrelia might be capable of negatively influencing this signaling, as primary human macrophages challenged with Borrelia showed decreased expression of MHCII ex vivo [100]. Further research into this interaction is necessary to evaluate these seemingly discrepant data and understand the processes which might be involved in the pathways for antigen presentation and their potential subversion by borreliae.

\section{Interactions among Macrophages and Other Immune Cells during Borrelia Infection}

The immune response to Borrelia infection involves many parts of the innate and the adaptive immune system, linked by cytokines and antigen presentation. Cells of the innate immune system are the first line of defense against the spirochete, and include macrophages; polymorphonuclear leukocytes, i.e., neutrophils, eosinophils and basophils; dendritic cells; mast cells; fibroblasts and keratinocytes. Cells of the adaptive immune response consist of $\mathrm{CD} 4+, \mathrm{CD} 8+, \gamma \delta$ and natural killer (NK) T-cells, and B cells [36].

Dermal fibroblasts are some of the first cells to encounter Borrelia during infection. In addition to remodeling of the extracellular matrix, they also play an active role in the context of inflammation by communicating with cells of the immune system and are thus considered to be part of the immune system. When challenged with Borrelia burgdorferi, human dermal fibroblasts showed increased release of IL-3, a cytokine which promotes macrophage activation and proliferation, and CCL2, a chemoattractant which draws macrophages to the site of infection (Figure 5) [101,102].

Skin samples from patients with Lyme disease showed elevated levels of IFN- $\gamma$ and $\mathrm{TNF} \alpha$ [102], hinting at the involvement of other cell types in macrophage activation during Borrelia infection. IFN- $\gamma$ is primarily released by T-cells, including NKT cells [103-105], whereas $\mathrm{TNF} \alpha$ is secreted by macrophages. Both cytokines target and activate macrophages [106].

As antigen presenting cells, dendritic cells and macrophages play crucial roles in the initiation of the adaptive immune response. Following the degradation in the phagolysosome, peptide-MHC II complexes are formed and travel to the cell surface, where they are presented to other immune cells and are especially important for a targeted T-cell response [98,99]. Interestingly, peripheral blood mononuclear cells co-cultured with Borrelia burgdorferi expressed and released a range of pro-inflammatory cytokines, mostly in an NF-kB- and MyD88-dependant manner, including IFN- $\gamma$, IL12, IL6, IL1, IL8 and TNF- $\alpha$ [107]. The production of type I interferons depends on the phagocytosis of Borrelia and on recognition of the pathogen within the phagolysosome by TLR7 and TLR 9, as inhibition of phagocytosis using cytochalasin D or combined inhibition of TLR7 and TLR9 using specific inhibitors abolishes production of IFN- $\alpha$ [107]. 


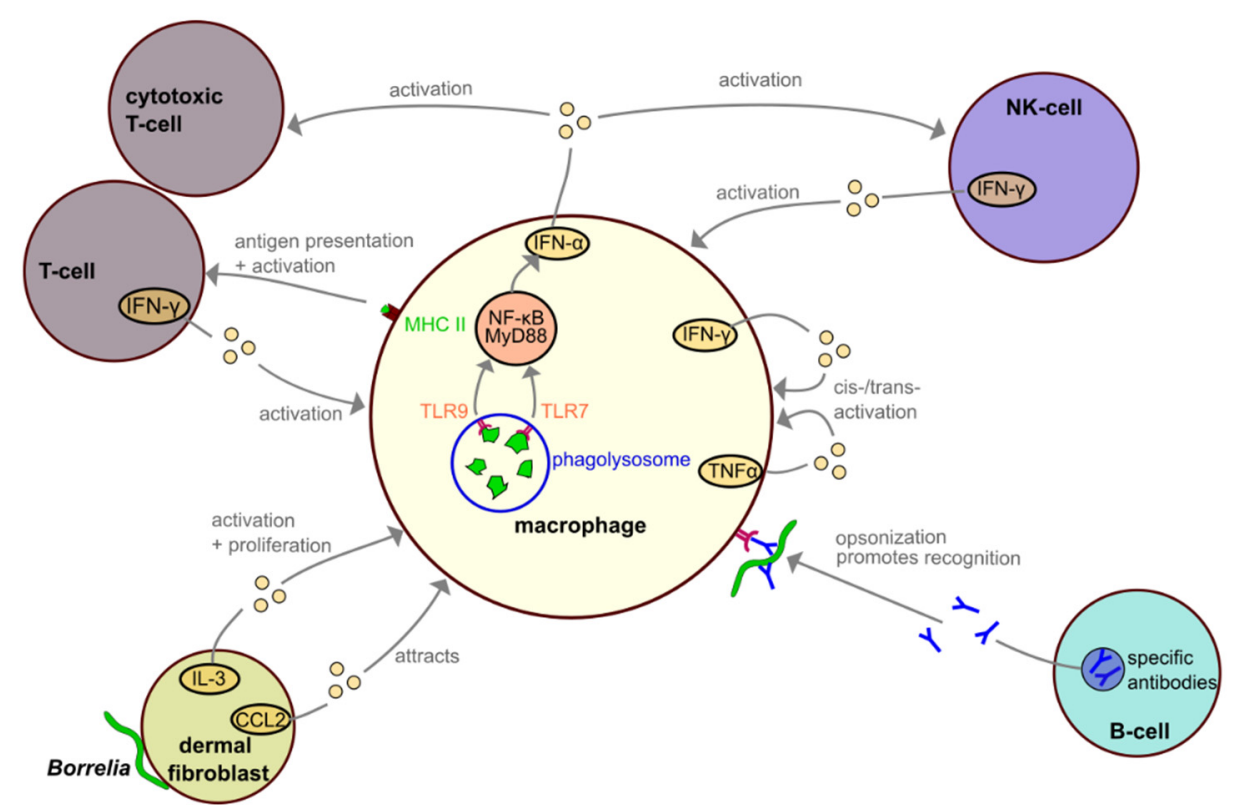

Figure 5. Interactions among macrophages and other immune cells during Borrelia infection. Dermal fibroblasts release IL-3 and CCL2 upon encountering Borrelia. Activated T-cells and NK-cells, including NKT cells, release IFN- $\gamma$. IL-3, CCL2 and IFN- $\gamma$ activate or attract macrophages. TLR7 and TLR9 recognize Borrelia in phagolysosomes and stimulate IFN- $\alpha$ release in NF- $\mathrm{BB}$ or MyD88dependent pathways. Macrophages present Borrelia antigens on MHC II-peptide complexes, leading to T-cell activation.

\section{Potential Immune Evasion Strategies of Borrelia}

Not every infection with Borrelia can be completely controlled by the immune system, allowing the development of Lyme disease. In this respect, Borrelia could even be recultivated from mouse samples 360 days after the initial inoculation [108]. Comparable evidence for prolonged microbial persistence in humans is lacking, but in some patients, symptoms associated with Lyme disease are known to persist for several months after antibiotic treatment. Whether this is due to microbial persistence, immune dysregulation or other factors is still a matter for debate [16]. In general, mechanisms for immune evasion and escape from phagocytic degradation have been described for different pathogens [29], and Borrelia burgdorferi shows a variety of evasion strategies as well.

As previously discussed, borreliae are highly motile, and as such could potentially attempt to escape from the proximity of phagocytic cells. Supporting this hypothesis, membrane tunnels have been observed in primary human macrophages, which extend deeper into the host cytoplasm than the actual Borrelia-containing phagosome. Most likely, these structures constitute parts of the nascent phagosome from which the spirochetes manage to extract themselves partially [56]. This dynamic interplay between pathogen and phagocyte would also be in line with the initial requirement for filopodia as pathogenimmobilizing structures, as they help to keep the motile spirochetes near the host cell surface until the more elaborate coiling pseudopod is formed. This seems to be especially important, considering that borreliae can reach velocities of up to $4.25 \mathrm{~nm} / \mathrm{s}$ [6], whereas macrophages show speeds of up to $10 \mu \mathrm{m} / \mathrm{min}$ [109-111], and are thus $\sim 25 \times$ slower than their bacterial prey.

Even after phagocytic uptake by macrophages, a small subpopulation of Borrelia escapes degradation and survives within the macrophage [86]. Usually, the elongated spirochete is compacted within the phagosome into a globular structure, but in some experiments (1-5\% of uptake events), Borrelia acquired a phagosomal coat only transiently during uptake and subsequently retained their elongated morphology [21]. The molecular mechanisms involved in this phenomenon are currently unknown. Still, reduced compaction of spirochetes as a result of siRNA-mediated knockdown of phagosomal coat proteins was 
correlated with increased intracellular survival, as it was possible to recultivate significantly more viable Borrelia from lysates of macrophages depleted in Rab5a, Rab22a or SNX3 than from control samples $[21,60]$. Whether these phenomena are causally linked is yet to be proven, but the observed correlation between compaction and degradation suggests that compaction is likely a necessary step in the processing of the pathogen. Similar results have previously been observed in Vero cells, where a subpopulation of Borrelia was not contained within a phagosomal membrane, an effect which was abrogated when using heat-killed Borrelia, suggesting active evasion from phagosomal degradation [112]. Other pathogens, such as Mycobacterium tuberculosis, are known to target RabGTPases and their effectors or PI(3)P and other components of the phagosomal membrane to arrest phagosomal maturation [29]. Whether similar mechanisms are actively employed by Borrelia to escape phagocytosis by macrophages is currently unknown.

Of course, the best defense against phagocytes is to stay out of their way in the first place. As Borrelia are transmitted by tick bites, they take advantage of the conditions provided by tick saliva. Tick saliva contains a number of active reagents that lead to vasodilation, supporting increased blood flow and distribution of the pathogen [113]. Moreover, proteins such as Salp20 inhibit the complement system [114], thereby preventing opsonization. In line with this, defects in opsonization were shown to lead to reduced internalization of Borrelia by macrophages [42].

A further immune evasion strategy consists of binding the host complement regulator factor $\mathrm{H}(\mathrm{FH})$, which includes factor H-binding proteins such as CspA and CspZ, and likely OspE. For more details on complement evasion, the reader is referred to several recent reviews [115-117]. In addition, Borrelia burgdorferi has been shown to establish a protective niche for itself and evade the humoral immune response by upregulating the decorin binding protein A (DbpA). Of note, DbpA's interaction partner decorin is highly expressed in the skin and joints, two major sites of infection in the context of Lyme disease. In mice, Borrelia loads were increased in these tissues with high decorin expression, promoting symptomatic manifestations, and spirochetes could still be recultivated from joint punctates 15 weeks after infection [118]. Borrelia clearance was found to negatively correlate with decorin expression in the tissue and DbpA expression by the spirochete. Furthermore, decorin-deficient mice showed increased pathogen clearance [119].

Collectively, these molecular mechanisms of evading the immune system could support prolonged survival of borreliae within the human host. However, it is currently unclear whether, and if so, to which degree, persisting symptoms reported in some patients are associated with survival of borreliae, or are based on dysregulation of the patients' immune systems. At the least, these evasion methods certainly have roles to play in the initial confrontation between the immune cells of the host and the pathogen.

\section{Concluding Remarks and Open Questions}

As Lyme disease is the most common tick-borne disease in North America and Europe [2], it is important to understand the underlying pathology. The host immune response against the causative agent, Borrelia spirochetes, is a crucial part of the defense against the disease. As professional phagocytes, macrophages play an important part in the attempt to eradicate the pathogen. Moreover, recent research has uncovered important molecular mechanisms involved in the uptake and initial processing of borreliae. The phagocytic process of Borrelia thus consists of multiple steps: (I) recognition by surface receptors, and capturing and immobilization by filopodia; (II) internalization by coiling pseudopods; (III) compaction in phagosomes; (IV) degradation in phagolysosomes; and (V) antigen presentation on MHC II complexes. Both dysregulation of individual steps during this process, and potentially also active evasion mechanisms employed by Borrelia, could be involved in the pathogenesis of the disease.

Still, the molecular mechanisms behind many steps in the cascade of the intracellular processing of Borrelia are only incompletely understood (Figure 6). These include (1) the roles of the ER and phagosomal phospholipids in phagosome maturation, (2) the observed 
relevance of the compaction process for phagosome maturation, (3) the likely involvement of alternative pathways in this phenomenon that are independent of the described Rab22aRab5a-SNX3-galectin-9 axis, (4) the mechanisms regulating membrane tubulation and abscission at phagosomes, (5) the mechanisms involved in loss of the phagosomal coat of a subset of internalized borreliae, (6) the likely involvement of additional regulators and vesicle populations in phagosome maturation, (7) the mechanisms regulating membrane fusion between vesicles and maturing phagolysosomes and (8) the nature of the degradative machinery within mature phagolysosomes.

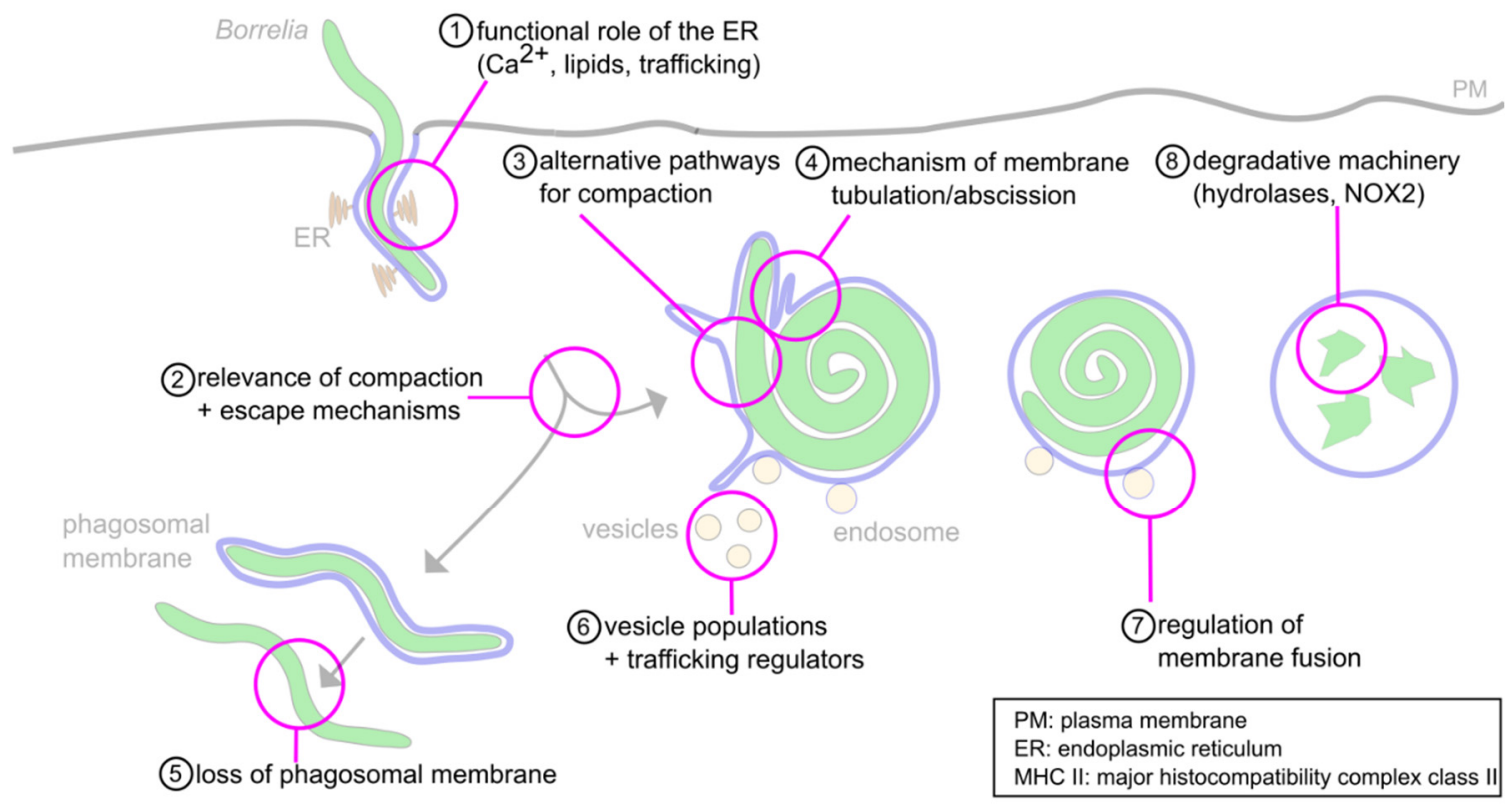

Figure 6. Open questions about the intracellular processing of Borrelia. (1) The functions of the ER-phagosome contact sites during phagosome compaction and maturation are still unknown. Likely functions concern $\mathrm{Ca}^{2+-}$ signaling, lipid transfer and regulation of trafficking. (2) The relevance of phagosome compaction for further phagolysosome maturation has been documented. However, the molecular basis for this requirement is unclear. (3) While some regulators of compaction have been identified, their individual or combined depletion leads to only a 50\% reduction of compaction, indicating the likely involvement of alternative pathways. (4) Compaction is accompanied by the extrusion and abscission of membrane tubules; however, the underlying molecular mechanisms are unclear. (5) A subpopulation (1-5\%) of Borrelia lose the phagosomal membrane and retain their elongated morphology. The mechanisms for this process, and its potential importance for survival in the host, are unclear. (6) The phagosome is contacted by Rab5a/SNX3 and galectin-9/flotillin-2 vesicles. Involvement of other regulatory cargo proteins and lipids, along with further vesicle populations, is likely but unproven. (7) The interaction between vesicles and the phagosomal membrane likely happens in a "kiss-and-run" fashion. The molecular mechanisms are unknown. (8) The degradative machinery is well described for other phagocytic targets. However, it is unknown whether the same enzymes, such as cathepsins and NOX-2, are also involved in proteolytic processing of Borrelia.

(1) The observed STIM-1-positive contact sites between the ER and the early stages of the Borrelia-containing phagosome should be an interesting field for future research, as little is known about their functions during this process. Multiple roles have been suggested for such contact sites in general, such as local $\mathrm{Ca}^{2+}$ signaling and exchange of lipids and proteins [90]. Additionally, changes in the composition of the phagosomal membrane could be important for the maturation of the organelle, comparably to the documented role of $\mathrm{PI}(3) \mathrm{P}$ in the docking of at least two distinct vesicle populations, leading to phagosome compaction. As other pathogens are known to influence the lipid compositions of membranes as a means to escape immune cells, ER-phagosome contact sites and the composition of the phagosomal membrane should be worth a more detailed investigation.

(2) Uptake and compaction of the highly motile and elongated borreliae requires finely tuned reorganization and restructuring of the cytoskeleton and the phagosomal membrane. Compaction of the spirochete was shown to be a prerequisite for phagosomal maturation 
and seems to be essential for eventual elimination of the pathogen. However, the reasons for it and the respective molecular mechanisms are only understood in part.

(3) For example, some regulators involved in the pathways leading to phagosomal compaction have already been identified; however, the involvement of other, yet unidentified pathways is likely.

(4) Furthermore, phagosome compaction is associated with reduction of phagosomal surface, which is based on the formation and abscission of membrane tubules. However, the molecular mechanisms involved in the tubulation and abscission are unknown.

(5) A subset of borreliae have been observed to retain their elongated form and lose the phagosomal coat [21]. However, it is currently unknown whether this is an active process driven by the pathogen, and if so, which mechanisms are responsible.

The maturation process which transforms the cell membrane-derived nascent phagosome into a phagolysosome capable of destroying the pathogen calls for tightly regulated interaction with other organelles and vesicles. Dysregulation of these processes, either during pathogen uptake or phagosome maturation, whether by a malfunction in a pathway or by active subversion by the pathogen, might lead to increased severity of the disease. It is thus vital to understand both the pathways involved in the regulation of phagocytosis and the potential immune evasion mechanisms employed by Borrelia to escape their degradation.

In recent years, multiple proteins have been identified that play pivotal roles in the regulation of Borrelia uptake and intracellular processing. Compaction of the phagosome and the trafficking of vesicles to the phagosome, along with their fusion and fission with the phagosomal membrane, are regulated by GTPases of the Rab family, by sorting nexin-3 and by galectin-9. Several RabGTPases have been identified as players in the maturation process of phagosomes of other phagocytic targets. Still, in the case of Borrelia, only the particular importance of Rab5a and Rab22a for uptake, compaction and degradation has been demonstrated yet. Of note, other pathogens such as Mycobacteria escape degradation by targeting those RabGTPases. The fact that a subset of internalized borreliae lose their Rab22a-positive phagosomal coat could point to the existence of comparable, but so far hypothetical mechanisms for the intracellular survival of Borrelia.

$(6,7)$ The mechanisms involved in phagosomal membrane fusion or contact events are currently only understood in part. Other vesicle populations and regulators than those previously described might yet be identified.

(8) Moreover, little is known about the regulation and relevant enzymes of late-stage phagolysosomes and the eventual degradation of internalized spirochetes. In this regard, cathepsins and NADPH oxidase 2 (NOX2) appear as likely candidates, as they have been observed in lysosomes and phagolysosomes of other phagocytic targets.

Apart from the usual suspects, other players seem to be involved in the processes related to phagocytosis, as new proteins have been found within or in the proximity of phagosomes [120], and functional roles have been documented for some of those proteins. An emerging but so far underappreciated, field concerns the metabolic pathways of the host cell. With the topic of immunometabolism gaining more prominence in recent years, further research in this area, especially in the context of pathogen processing, and specifically Borrelia elimination, seems promising.

In summary, closely regulated changes in phagosomal morphology and composition are central for the successful elimination of Borrelia. Accordingly, several regulators of intracellular trafficking have already been linked to this process, but many more might be involved. Additionally, borreliae have emerged as being far from passive targets, which actively counteract their capturing and internalization by immune cells. It would thus be highly interesting to see whether borreliae also employ more active mechanisms to influence their intracellular processing and how these could contribute to the pathology of Lyme disease. 
Author Contributions: Conceptualization, P.W. and S.L.; writing-original draft preparation, P.W.; writing-review and editing, S.L.; visualization, P.W. and S.L.; supervision, S.L.; project administration, S.L.; funding acquisition, S.L. All authors have read and agreed to the published version of the manuscript.

Funding: This work was supported by grants from the Deutsche Forschungsgemeinschaft (GRK1459, CRC877, LI925/11-1).

Institutional Review Board Statement: Not applicable.

Informed Consent Statement: Not applicable.

Data Availability Statement: Not applicable.

Acknowledgments: We apologize to all authors whose work was not mentioned owing to space limitations. We thank Andrea Mordhorst for expert technical assistance and Martin Aepfelbacher for continuous support.

Conflicts of Interest: The authors declare no conflict of interest.

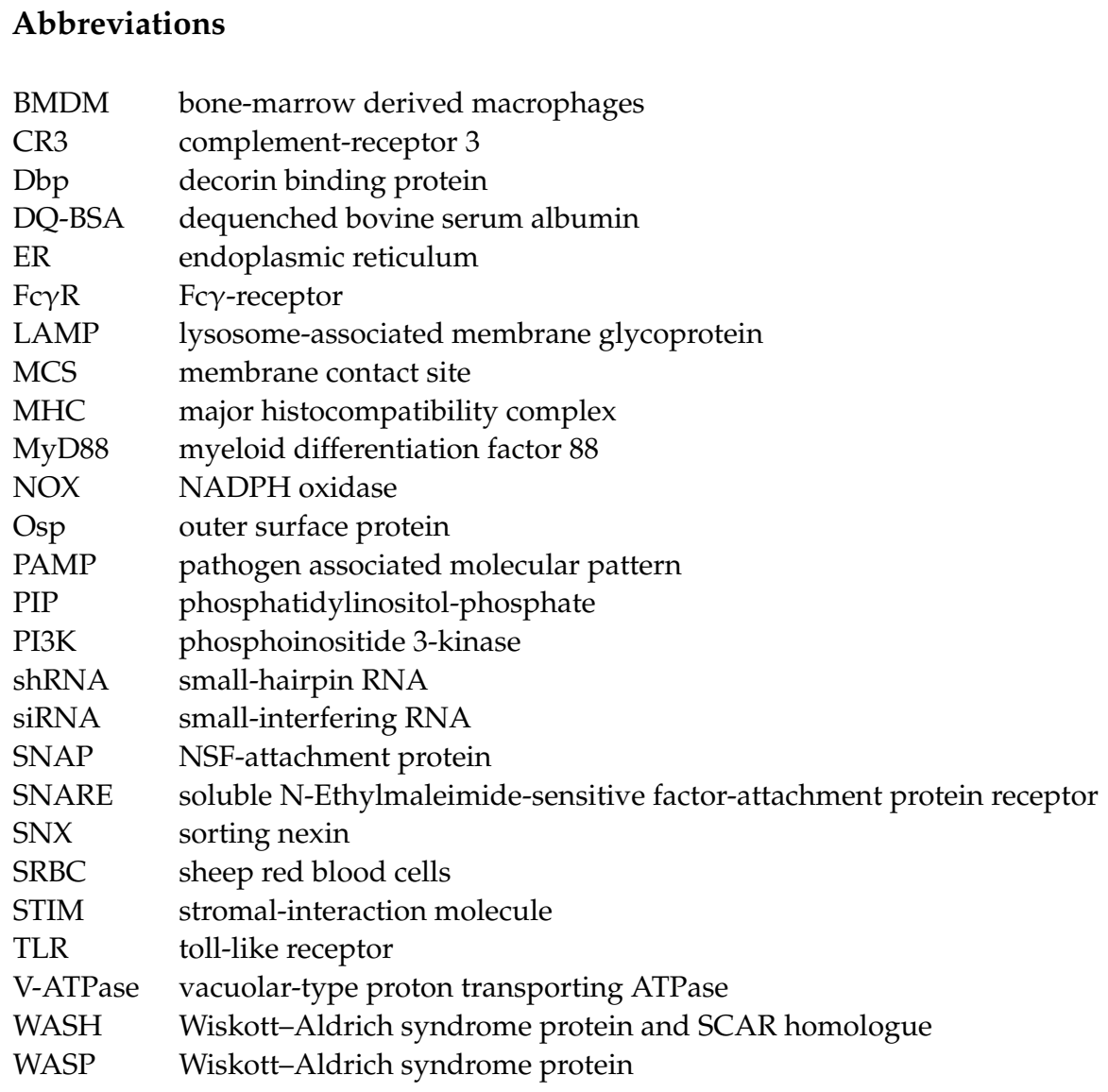

\section{References}

1. Russell, A.L.R.; Dryden, M.S.; Pinto, A.A.; Lovett, J.K. Lyme disease: Diagnosis and management. Pr. Neurol. 2018, 18, 455-464. [CrossRef] [PubMed]

2. Mead, P.S. Epidemiology of Lyme Disease. Infect. Dis. Clin. N. Am. 2015, 29, 187-210. [CrossRef] [PubMed]

3. Steere, A.C.; Malawista, S.E.; Snydman, D.R.; Shope, R.E.; Andiman, W.A.; Ross, M.R.; Steele, F.M. An epidemic of oligoarticular arthritis in children and adults in three connecticut communities. Arthritis Rheum. 1977, 20, 7-17. [CrossRef] [PubMed]

4. Burgdorfer, W.; Barbour, A.G.; Hayes, S.F.; Benach, J.L.; Grunwaldt, E.; Davis, J.P. Lyme disease-a tick-borne spirochetosis? Science 1982, 216, 1317-1319. [CrossRef]

5. Aberer, E.; Duray, P.H. Morphology of Borrelia burgdorferi: Structural patterns of cultured borreliae in relation to staining methods. J. Clin. Microbiol. 1991, 29, 764-772. [CrossRef]

6. Goldstein, S.F.; Charon, N.W.; Kreiling, J.A. Borrelia burgdorferi swims with a planar waveform similar to that of eukaryotic flagella. Proc. Natl. Acad. Sci. USA 1994, 91, 3433-3437. [CrossRef] 
7. Cutler, S.J.; Ruzic-Sabljic, E.; Potkonjak, A. Emerging borreliae-Expanding beyond Lyme borreliosis. Mol. Cell. Probes 2017, 31, 22-27. [CrossRef]

8. Lane, R.S.; Loye, J.E. Lyme Disease in California: Interrelationship of Ixodid Ticks (Acari), Rodents, and Borrelia burgdorferi. J. Med. Èntomol. 1991, 28, 719-725. [CrossRef]

9. Gern, L. Borrelia burgdorferi sensu lato, the agent of Lyme borreliosis: Life in the wilds. Parasite 2008, 15, 244-247. [CrossRef]

10. Margos, G.; Vollmer, S.A.; Ogden, N.H.; Fish, D. Population genetics, taxonomy, phylogeny and evolution of Borrelia burgdorferi sensu lato. Infect. Genet. Evol. 2011, 11, 1545-1563. [CrossRef]

11. Bacon, R.M.; Kugeler, K.J.; Mead, P.S. Surveillance for Lyme Disease-United States, 1992-2006. Available online: https: //www.cdc.gov/mmwr/preview/mmwrhtml/ss5710a1.htm (accessed on 10 April 2021).

12. Ogden, N.H.; Feil, E.J.; Leighton, P.A.; Lindsay, L.R.; Margos, G.; Mechai, S.; Michel, P.; Moriarty, T.J. Evolutionary Aspects of Emerging Lyme Disease in Canada. Appl. Environ. Microbiol. 2015, 81, 7350-7359. [CrossRef]

13. Schoen, R.T. Lyme disease: Diagnosis and treatment. Curr. Opin. Rheumatol. 2020, 32, 247-254. [CrossRef]

14. Salazar, J.C.; Pope, C.D.; Sellati, T.J.; Feder, H.M.; Kiely, T.G.; Dardick, K.R.; Buckman, R.L.; Moore, M.W.; Caimano, M.J.; Pope, J.G.; et al. Coevolution of Markers of Innate and Adaptive Immunity in Skin and Peripheral Blood of Patients with Erythema Migrans. J. Immunol. 2003, 171, 2660-2670. [CrossRef]

15. Moriarty, T.J.; Norman, M.U.; Colarusso, P.; Bankhead, T.; Kubes, P.; Chaconas, G. Real-Time High Resolution 3D Imaging of the Lyme Disease Spirochete Adhering to and Escaping from the Vasculature of a Living Host. PLoS Pathog. 2008, 4, e1000090. [CrossRef]

16. Rebman, A.W.; Aucott, J.N. Post-treatment Lyme Disease as a Model for Persistent Symptoms in Lyme Disease. Front. Med. 2020, 7, 57. [CrossRef]

17. Steere, A.C.; Strle, F.; Wormser, G.P.; Hu, L.T.; Branda, J.A.; Hovius, J.W.R.; Li, X.; Mead, P.S. Lyme borreliosis. Nat. Rev. Dis. Prim. 2016, 2, 1-19. [CrossRef]

18. Naj, X.; Linder, S. Actin-Dependent Regulation of Borrelia burgdorferi Phagocytosis by Macrophages. Curr. Top. Microbiol. Immunol. 2016, 399, 133-154. [CrossRef]

19. Hoffmann, A.K.; Naj, X.; Linder, S. Daam1 is a regulator of filopodia formation and phagocytic uptake of Borrelia burgdorferi by primary human macrophages. FASEB J. 2014, 28, 3075-3089. [CrossRef]

20. Naj, X.; Hoffmann, A.-K.; Himmel, M.; Linder, S. The Formins FMNL1 and mDia1 Regulate Coiling Phagocytosis of Borrelia burgdorferi by Primary Human Macrophages. Infect. Immun. 2013, 81, 1683-1695. [CrossRef]

21. Naj, X.; Linder, S. ER-Coordinated Activities of Rab22a and Rab5a Drive Phagosomal Compaction and Intracellular Processing of Borrelia burgdorferi by Macrophages. Cell Rep. 2015, 12, 1816-1830. [CrossRef]

22. Niedergang, F. Phagocytosis. In Encyclopedia of Cell Biology; Bradshaw, R.A., Stahl, P.D., Eds.; Academic Press: Waltham, MA, USA, 2016; pp. 751-757.

23. Flannagan, R.; Jaumouillé, V.; Grinstein, S. The Cell Biology of Phagocytosis. Annu. Rev. Pathol. Mech. Dis. 2012, 7, 61-98. [CrossRef]

24. Hoffmann, J.A.; Kafatos, F.C.; Janeway, C.A.; Ezekowitz, R.A.B. Phylogenetic Perspectives in Innate Immunity. Science 1999, 284, 1313-1318. [CrossRef]

25. Gordon, S. Phagocytosis: An Immunobiologic Process. Immunity 2016, 44, 463-475. [CrossRef]

26. Rabinovitch, M. Professional and non-professional phagocytes: An introduction. Trends Cell Biol. 1995, 5, 85-87. [CrossRef]

27. Benach, J.L.; Habicht, G.S.; Gocinski, B.L.; Coleman, J.L. Phagocytic cell responses to in vivo and in vitro expo-sure to the Lyme disease spirochete. Yale J. Biol. Med. 1984, 57, 599-605.

28. Montgomery, R.R.; Nathanson, M.H.; Malawista, S.E. Fc- and Non-Fc-Mediated Phagocytosis of Borrelia Burgdorferi by Maerophages. J. Infect. Dis. 1994, 170, 890-893. [CrossRef]

29. Flannagan, R.S.; Cosío, G.; Grinstein, S. Antimicrobial mechanisms of phagocytes and bacterial evasion strategies. Nat. Rev. Microbiol. 2009, 7, 355-366. [CrossRef]

30. Carreras-González, A.; Barriales, D.; Palacios, A.; Montesinos-Robledo, M.; Navasa, N.; Azkargorta, M.; Peña-Cearra, A.; Tomás-Cortázar, J.; Escobes, I.; Pascual-Itoiz, M.A.; et al. Regulation of macrophage activity by surface receptors contained within Borrelia burgdorferi-enriched phagosomal fractions. PLoS Pathog. 2019, 15, e1008163. [CrossRef]

31. Garcia, R.C.; Murgia, R.; Cinco, M. Complement Receptor 3 Binds the Borrelia burgdorferi Outer Surface Proteins OspA and OspB in an iC3b-Independent Manner. Infect. Immun. 2005, 73, 6138-6142. [CrossRef]

32. Cinco, M.; Murgia, R.; Presani, G.; Perticarari, S. Integrin CR3 mediates the binding of nonspecifically opsonized Borrelia burgdorferi to human phagocytes and mammalian cells. Infect. Immun. 1997, 65, 4784-4789. [CrossRef]

33. Hawley, K.L.; Olson, C.M.; Iglesias-Pedraz, J.M.; Navasa, N.; Cervantes, J.L.; Caimano, M.J.; Izadi, H.; Ingalls, R.; Pal, U.; Salazar, J.C.; et al. CD14 cooperates with complement receptor 3 to mediate MyD88-independent phagocytosis of Borrelia burgdorferi. Proc. Natl. Acad. Sci. USA 2012, 109, 1228-1232. [CrossRef] [PubMed]

34. Wooten, R.M.; Ma, Y.; Yoder, R.A.; Brown, J.P.; Weis, J.H.; Zachary, J.F.; Kirschning, C.J.; Weis, J.J. Toll-Like Receptor 2 Is Required for Innate, But Not Acquired, Host Defense to Borrelia burgdorferi. J. Immunol. 2002, 168, 348-355. [CrossRef] [PubMed]

35. Salazar, J.C.; Duhnam-Ems, S.; La Vake, C.; Cruz, A.R.; Moore, M.W.; Caimano, M.J.; Velez-Climent, L.; Shupe, J.; Krueger, W.; Radolf, J.D. Activation of Human Monocytes by Live Borrelia burgdorferi Generates TLR2-Dependent and -Independent Responses Which Include Induction of IFN- $\beta$. PLoS Pathog. 2009, 5, e1000444. [CrossRef] [PubMed] 
36. Verhaegh, D.; Joosten, L.A.; Oosting, M. The role of host immune cells and Borrelia burgdorferi antigens in the etiology of Lyme disease. Eur. Cytokine Netw. 2017, 28, 70-84. [CrossRef]

37. Benjamin, S.J.; Hawley, K.L.; Vera-Licona, P.; La Vake, C.J.; Cervantes, J.L.; Ruan, Y.; Radolf, J.D.; Salazar, J.C. Macrophage mediated recognition and clearance of Borrelia burgdorferi elicits MyD88-dependent and -independent phagosomal signals that contribute to phagocytosis and inflammation. BMC Immunol. 2021, 22, 1-16. [CrossRef]

38. Shin, O.S.; Miller, L.S.; Modlin, R.L.; Akira, S.; Uematsu, S.; Hu, L.T. Downstream Signals for MyD88-Mediated Phagocytosis of Borrelia burgdorferi can be Initiated by TRIF and Are Dependent on PI3K. J. Immunol. 2009, 183, 491-498. [CrossRef]

39. Wang, G.; Ma, Y.; Buyuk, A.; McClain, S.; Weis, J.J.; Schwartz, I. Impaired host defense to infection and Toll-like receptor 2-independent killing of Borrelia burgdorferi clinical isolates in TLR2-deficient C3H/HeJ mice. FEMS Microbiol. Lett. 2004, 231, 219-225. [CrossRef]

40. Lawrenz, M.B.; Wooten, R.M.; Zachary, J.F.; Drouin, S.M.; Weis, J.J.; Wetsel, R.A.; Norris, S.J. Effect of Complement Component C3 Deficiency on Experimental Lyme Borreliosis in Mice. Infect. Immun. 2003, 71, 4432-4440. [CrossRef]

41. Montgomery, R.R.; Malawista, S.E. Borrelia burgdorferi and the macrophage: Routine annihilation but occasional haven? Parasitol. Today 1994, 10, 154-157. [CrossRef]

42. Linder, S.; Heimerl, C.; Fingerle, V.; Aepfelbacher, M.; Wilske, B. Coiling Phagocytosis of Borrelia burgdorferi by Primary Human Macrophages Is Controlled by CDC42Hs and Rac1 and Involves Recruitment of Wiskott-Aldrich Syndrome Protein and Arp2/3 Complex. Infect. Immun. 2001, 69, 1739-1746. [CrossRef]

43. Flannagan, R.S.; Harrison, R.E.; Yip, C.M.; Jaqaman, K.; Grinstein, S. Dynamic macrophage "probing" is required for the efficient capture of phagocytic targets. J. Cell Biol. 2010, 191, 1205-1218. [CrossRef]

44. Mallavarapu, A.; Mitchison, T. Regulated Actin Cytoskeleton Assembly at Filopodium Tips Controls Their Extension and Retraction. J. Cell Biol. 1999, 146, 1097-1106. [CrossRef]

45. Svitkina, T.M.; Bulanova, E.A.; Chaga, O.Y.; Vignjevic, D.M.; Kojima, S.-I.; Vasiliev, J.M.; Borisy, G.G. Mechanism of filopodia initiation by reorganization of a dendritic network. J. Cell Biol. 2003, 160, 409-421. [CrossRef]

46. Bohnert, K.A.; Willet, A.H.; Kovar, D.R.; Gould, K.L. Formin-based control of the actin cytoskeleton during cytokinesis. Biochem. Soc. Trans. 2013, 41, 1750-1754. [CrossRef]

47. Li, F.; Higgs, H.N. The Mouse Formin mDia1 Is a Potent Actin Nucleation Factor Regulated by Autoinhibition. Curr. Biol. 2003, 13, 1335-1340. [CrossRef]

48. Harris, E.S.; Li, F.; Higgs, H.N. The Mouse Formin, FRL $\alpha$, Slows Actin Filament Barbed End Elongation, Competes with Capping Protein, Accelerates Polymerization from Monomers, and Severs Filaments. J. Biol. Chem. 2004, 279, 20076-20087. [CrossRef]

49. Amann, K.J.; Pollard, T.D. The Arp2/3 complex nucleates actin filament branches from the sides of pre-existing filaments. Nat. Cell Biol. 2001, 3, 306-310. [CrossRef]

50. Young, L.E.; Heimsath, E.G.; Higgs, H.N. Cell type-dependent mechanisms for formin-mediated assembly of filopodia. Mol. Biol. Cell 2015, 26, 4646-4659. [CrossRef]

51. Kress, H.; Stelzer, E.H.K.; Holzer, D.; Buss, F.; Griffiths, G.; Rohrbach, A. Filopodia act as phagocytic tentacles and pull with discrete steps and a load-dependent velocity. Proc. Natl. Acad. Sci. USA 2007, 104, 11633-11638. [CrossRef]

52. Vonna, L.; Wiedemann, A.; Aepfelbacher, M.; Sackmann, E. Micromechanics of filopodia mediated capture of pathogens by macrophages. Eur. Biophys. J. 2007, 36, 145-151. [CrossRef]

53. Heidemann, S.R.; Lamoureux, P.; Buxbaum, R.E. Growth cone behavior and production of traction force. J. Cell Biol. 1990, 111, 1949-1957. [CrossRef]

54. Rittig, M.G.; Krause, A.; Häupl, T.; Schaible, U.E.; Modolell, M.; Kramer, M.D.; Lütjen-Drecoll, E.; Simon, M.M.; Burmester, G.R. Coiling phagocytosis is the preferential phagocytic mechanism for Borrelia burgdorferi. Infect. Immun. 1992, 60, 4205-4212. [CrossRef]

55. Rittig, M.G.; Wilske, B.; Krause, A. Phagocytosis of microorganisms by means of overshooting pseudopods: Where do we stand? Microbes Infect. 1999, 1, 727-735. [CrossRef]

56. Klose, M.; Scheungrab, M.; Luckner, M.; Wanner, G.; Linder, S. FIB/SEM-based analysis of Borrelia intracellular processing by human macrophages. J. Cell Sci. 2021, 134. [CrossRef]

57. Rittig, M.G.; Jagoda, J.C.; Wilske, B.; Murgia, R.; Cinco, M.; Repp, R.; Burmester, G.R.; Krause, A. Coiling Phagocytosis Discriminates between Different Spirochetes and Is Enhanced by Phorbol Myristate Acetate and Granulocyte- Macrophage Colony-Stimulating Factor. Infect. Immun. 1998, 66, 627-635. [CrossRef]

58. Mullins, R.D. How WASP-family proteins and the Arp2/3 complex convert intracellular signals into cytoskeletal structures. Curr. Opin. Cell Biol. 2000, 12, 91-96. [CrossRef]

59. Vieira, O.V.; Botelho, R.J.; Grinstein, S. Phagosome maturation: Aging gracefully. Biochem. J. 2002, 366, 689-704. [CrossRef]

60. Klose, M.; Salloum, J.E.; Gonschior, H.; Linder, S. SNX3 drives maturation of Borrelia phagosomes by forming a hub for PI(3)P, Rab5a, and galectin-9. J. Cell Biol. 2019, 218, 3039-3059. [CrossRef] [PubMed]

61. Zerial, M.; McBride, H. Rab proteins as membrane organizers. Nat. Rev. Mol. Cell Biol. 2001, 2, 107-117. [CrossRef] [PubMed]

62. Worby, C.A.; Dixon, J.E. Sorting out the cellular functions of sorting nexins. Nat. Rev. Mol. Cell Biol. 2002, 3, 919-931. [CrossRef] [PubMed]

63. Johannes, L.; Jacob, R.; Leffler, H. Galectins at a glance. J. Cell Sci. 2018, 131, 208884. [CrossRef] 
64. Hubner, S.; Couvillon, A.D.; Kas, J.A.; Bankaitis, V.A.; Vegners, R.; Carpenter, C.L.; Janmey, P.A. Enhancement of phosphoinositide 3-kinase (PI 3-kinase) activity by membrane curvature and inositol-phospholipid-binding peptides. Eur. J. Biochem. 1998, 258, 846-853. [CrossRef]

65. Meister, M.; Tikkanen, R. Endocytic Trafficking of Membrane-Bound Cargo: A Flotillin Point of View. Membranes 2014, 4, 356-371. [CrossRef]

66. Friedman, J.R.; DiBenedetto, J.R.; West, M.; Rowland, A.A.; Voeltz, G.K. Endoplasmic reticulum-endosome contact increases as endosomes traffic and mature. Mol. Biol. Cell 2013, 24, 1030-1040. [CrossRef]

67. Desjardins, M.; Huber, L.A.; Parton, R.G.; Griffiths, G. Biogenesis of phagolysosomes proceeds through a sequential series of interactions with the endocytic apparatus. J. Cell Biol. 1994, 124, 677-688. [CrossRef]

68. Mayorga, L.S.; Cebrian, I. Rab22a: A novel regulator of immune functions. Mol. Immunol. 2019, 113, 87-92. [CrossRef]

69. Bucci, C.; Parton, R.; Mather, I.H.; Stunnenberg, H.; Simons, K.; Hoflack, B.; Zerial, M. The small GTPase rab5 functions as a regulatory factor in the early endocytic pathway. Cell 1992, 70, 715-728. [CrossRef]

70. Feng, Y.; Press, B.; Wandinger-Ness, A. Rab 7: An important regulator of late endocytic membrane traffic. J. Cell Biol. 1995, 131, 1435-1452. [CrossRef]

71. Gutierrez, M.G. Functional role(s) of phagosomal Rab GTPases. Small GTPases 2013, 4, 148-158. [CrossRef]

72. Via, L.E.; Deretic, D.; Ulmer, R.J.; Hibler, N.S.; Huber, L.A.; Deretic, V. Arrest of Mycobacterial Phagosome Maturation Is Caused by a Block in Vesicle Fusion between Stages Controlled by rab5 and rab7. J. Biol. Chem. 1997, 272, 13326-13331. [CrossRef]

73. Desjardins, M. Biogenesis of phagolysosomes: The 'kiss and run' hypothesis. Trends Cell Biol. 1995, 5, 183-186. [CrossRef]

74. Pauwels, A.-M.; Trost, M.; Beyaert, R.; Hoffmann, E. Patterns, Receptors, and Signals: Regulation of Phagosome Maturation. Trends Immunol. 2017, 38, 407-422. [CrossRef]

75. Rothman, J.E.; Warren, G. Implications of the SNARE hypothesis for intracellular membrane topology and dynamics. Curr. Biol. 1994, 4, 220-233. [CrossRef]

76. Christoforidis, S.; McBride, H.M.; Burgoyne, R.D.; Zerial, M. The Rab5 effector EEA1 is a core component of endosome docking. Nat. Cell Biol. 1999, 397, 621-625. [CrossRef] [PubMed]

77. McBride, H.M.; Rybin, V.; Murphy, C.; Giner, A.; Teasdale, R.; Zerial, M. Oligomeric Complexes Link Rab5 Effectors with NSF and Drive Membrane Fusion via Interactions between EEA1 and Syntaxin 13. Cell 1999, 98, 377-386. [CrossRef]

78. Linardopoulou, E.V.; Parghi, S.S.; Friedman, C.; Osborn, G.E.; Parkhurst, S.M.; Trask, B.J. Human Subtelomeric WASH Genes Encode a New Subclass of the WASP Family. PLoS Genet. 2007, 3, e237. [CrossRef]

79. King, J.S.; Gueho, A.; Hagedorn, M.; Gopaldass, N.; Leuba, F.; Soldati, T.; Insall, R.H. WASH is required for lysosomal recycling and efficient autophagic and phagocytic digestion. Mol. Biol. Cell 2013, 24, 2714-2726. [CrossRef]

80. Bozzaro, S.; Bucci, C.; Steinert, M. Phagocytosis and Host-Pathogen Interactions in Dictyostelium with a Look at Macrophages. Int. Rev. Cell Mol. Biol. 2008, 271, 253-300. [CrossRef] [PubMed]

81. Kjeken, R.; Egeberg, M.; Habermann, A.; Kuehnel, M.; Peyron, P.; Floetenmeyer, M.; Walther, P.; Jahraus, A.; Defacque, H.; Kuznetsov, S.A.; et al. Fusion between Phagosomes, Early and Late Endosomes: A Role for Actin in Fusion between Late, but Not Early Endocytic Organelles. Mol. Biol. Cell 2004, 15, 345-358. [CrossRef] [PubMed]

82. Sun-Wada, G.-H.; Tabata, H.; Kawamura, N.; Aoyama, M.; Wada, Y. Direct recruitment of $\mathrm{H}^{+}$-ATPase from lysosomes for phagosomal acidification. J. Cell Sci. 2009, 122, 2504-2513. [CrossRef] [PubMed]

83. Pillay, C.S.; Elliott, E.; Dennison, C. Endolysosomal proteolysis and its regulation. Biochem. J. 2002, 363, 417-429. [CrossRef]

84. Rink, J.; Ghigo, E.; Kalaidzidis, Y.; Zerial, M. Rab Conversion as a Mechanism of Progression from Early to Late Endosomes. Cell 2005, 122, 735-749. [CrossRef]

85. Henry, R.M.; Hoppe, A.D.; Joshi, N.; Swanson, J.A. The uniformity of phagosome maturation in macrophages. J. Cell Biol. 2004, 164, 185-194. [CrossRef]

86. Montgomery, R.R.; Nathanson, M.H.; Malawista, S.E. The fate of Borrelia burgdorferi, the agent for Lyme disease, in mouse macrophages. Destruction, survival, recovery. J. Immunol. 1993, 150, 909-915.

87. Eskelinen, E.-L. Roles of LAMP-1 and LAMP-2 in lysosome biogenesis and autophagy. Mol. Asp. Med. 2006, $27,495-502$. [CrossRef]

88. Balla, T. $\mathrm{Ca}^{2+}$ and lipid signals hold hands at endoplasmic reticulum-plasma membrane contact sites. J. Physiol. 2018, 596, 2709-2716. [CrossRef]

89. Helle, S.C.; Kanfer, G.; Kolar, K.; Lang, A.; Michel, A.H.; Kornmann, B. Organization and function of membrane contact sites Biochim. Biophys. Acta (BBA) Mol. Cell Res. 2013, 1833, 2526-2541. [CrossRef]

90. Nunes-Hasler, P.; Demaurex, N. The ER phagosome connection in the era of membrane contact sites. Biochim. Biophys. Acta (BBA) Mol. Cell Res. 2017, 1864, 1513-1524. [CrossRef]

91. Rowland, A.A.; Chitwood, P.J.; Phillips, M.J.; Voeltz, G.K. ER Contact Sites Define the Position and Timing of Endosome Fission. Cell 2014, 159, 1027-1041. [CrossRef]

92. Nunes, P.; Demaurex, N. The role of calcium signaling in phagocytosis. J. Leukoc. Biol. 2010, 88, 57-68. [CrossRef]

93. Malik, Z.A.; Denning, G.M.; Kusner, D.J. Inhibition of $\mathrm{Ca}^{2+}$ Signaling by Mycobacterium tuberculosis is Associated with Reduced Phagosome-Lysosome Fusion and Increased Survival within Human Macrophages. J. Exp. Med. 2000, 191, 287-302. [CrossRef] 
94. Stockinger, W.; Zhang, S.C.; Trivedi, V.; Jarzylo, L.A.; Shieh, E.C.; Lane, W.S.; Castoreno, A.B.; Nohturfft, A. Differential Requirements for Actin Polymerization, Calmodulin, and $\mathrm{Ca}^{2+}$ Define Distinct Stages of Lysosome/Phagosome Targeting. Mol. Biol. Cell 2006, 17, 1697-1710. [CrossRef]

95. Marshall, J.G.; Booth, J.W.; Stambolic, V.; Mak, T.; Balla, T.; Schreiber, A.D.; Meyer, T.; Grinstein, S. Restricted Accumulation of Phosphatidylinositol 3-Kinase Products in a Plasmalemmal Subdomain during Fc $\gamma$ Receptor-Mediated Phagocytosis. J. Cell Biol. 2001, 153, 1369-1380. [CrossRef]

96. Vieira, O.V.; Botelho, R.J.; Rameh, L.; Brachmann, S.M.; Matsuo, T.; Davidson, H.W.; Schreiber, A.; Backer, J.M.; Cantley, L.C.; Grinstein, S. Distinct roles of class I and class III phosphatidylinositol 3-kinases in phagosome formation and maturation. J. Cell Biol. 2001, 155, 19-26. [CrossRef]

97. Levin, R.; Grinstein, S.; Schlam, D. Phosphoinositides in phagocytosis and macropinocytosis. Biochim. Biophys. Acta (BBA) Mol. Cell Biol. Lipids 2015, 1851, 805-823. [CrossRef]

98. Ramachandra, L.; Song, R.; Harding, C.V. Phagosomes are fully competent antigen-processing organelles that mediate the formation of peptide: Class II MHC complexes. J. Immunol. 1999, 162, 3263-3272.

99. Altenschmidt, U.; Ricciardi-Castagnoli, P.; Modolell, M.; Otto, H.; Wiesmüller, K.-H.; Jung, G.; Simon, M.M. Bone marrow-derived macrophage lines and immortalized cloned macrophage and dendritic cells support priming of Borrelia burgdorferi-specific $\mathrm{T}$ cell responses in vitro and/or in vivo. Immunol. Lett. 1996, 50, 41-49. [CrossRef]

100. Brouwer, M.A.; Jones-Warner, W.; Rahman, S.; Kerstholt, M.; Ferreira, A.V.; Oosting, M.; Hooiveld, G.J.; Netea, M.G.; Joosten, L.A. B. burgdorferi sensu lato-induced inhibition of antigen presentation is mediated by RIP1 signaling resulting in impaired functional T cell responses towards Candida albicans. Ticks Tick-Borne Dis. 2021, 12, 101611. [CrossRef]

101. Schramm, F.; Kern, A.; Barthel, C.; Nadaud, S.; Meyer, N.; Jaulhac, B.; Boulanger, N. Microarray Analyses of Inflammation Response of Human Dermal Fibroblasts to Different Strains of Borrelia burgdorferi Sensu Stricto. PLoS ONE 2012, 7, e40046. [CrossRef]

102. Müllegger, R.R.; Means, T.K.; Shin, J.J.; Lee, M.; Jones, K.L.; Glickstein, L.J.; Luster, A.D.; Steere, A.C. Chemokine Signatures in the Skin Disorders of Lyme Borreliosis in Europe: Predominance of CXCL9 and CXCL10 in Erythema Migrans and Acrodermatitis and CXCL13 in Lymphocytoma. Infect. Immun. 2007, 75, 4621-4628. [CrossRef]

103. Katchar, K.; Drouin, E.E.; Steere, A.C. Natural killer cells and natural killer T cells in Lyme arthritis. Arthritis Res. Ther. 2013, 15, R183. [CrossRef] [PubMed]

104. Olson, C.M.; Bates, T.C.; Izadi, H.; Radolf, J.D.; Huber, S.A.; Boyson, J.E.; Anguita, J. Local Production of IFN- $\gamma$ by Invariant NKT Cells Modulates Acute Lyme Carditis. J. Immunol. 2009, 182, 3728-3734. [CrossRef] [PubMed]

105. Sonderegger, F.L.; Ma, Y.; Maylor-Hagan, H.; Brewster, J.; Huang, X.; Spangrude, G.J.; Zachary, J.F.; Weis, J.H.; Weis, J.J. Localized Production of IL-10 Suppresses Early Inflammatory Cell Infiltration and Subsequent Development of IFN- $\gamma-$ Mediated Lyme Arthritis. J. Immunol. 2011, 188, 1381-1393. [CrossRef]

106. Turner, M.D.; Nedjai, B.; Hurst, T.; Pennington, D.J. Cytokines and chemokines: At the crossroads of cell signalling and inflammatory disease. Biochim. Biophys. Acta (BBA) Mol. Cell Res. 2014, 1843, 2563-2582. [CrossRef]

107. Petzke, M.M.; Brooks, A.; Krupna, M.A.; Mordue, D.; Schwartz, I. Recognition of Borrelia burgdorferi, the Lyme Disease Spirochete, by TLR7 and TLR9 Induces a Type I IFN Response by Human Immune Cells. J. Immunol. 2009, 183, $5279-5292$. [CrossRef]

108. Barthold, S.W.; De Souza, M.S.; Janotka, J.L.; Smith, A.L.; Persing, D.H. Chronic Lyme borreliosis in the laboratory mouse. Am. J. Pathol. 1993, 143, 959-971.

109. Rumianek, A.N.; Greaves, D.R. How Have Leukocyte In Vitro Chemotaxis Assays Shaped Our Ideas about Macrophage Migration? Biology 2020, 9, 439. [CrossRef]

110. Barros-Becker, F.; Lam, P.-Y.; Fisher, R.; Huttenlocher, A. Live imaging reveals distinct modes of neutrophil and macrophage migration within interstitial tissues. J. Cell Sci. 2017, 130, 3801-3808. [CrossRef]

111. Grabher, C.; Cliffe, A.; Miura, K.; Hayflick, J.; Pepperkok, R.; Rørth, P.; Wittbrodt, J. Birth and life of tissue macrophages and their migration in embryogenesis and inflammation in medaka. J. Leukoc. Biol. 2007, 81, 263-271. [CrossRef]

112. Hechemy, K.E.; Samsonoff, W.A.; Harris, H.L.; McKee, M. Adherence and entry of Borrelia burgdorferi in Vero cells. J. Med. Microbiol. 1992, 36, 229-238. [CrossRef]

113. Kazimírová, M.; Štibrániová, I. Tick salivary compounds: Their role in modulation of host defences and pathogen transmission. Front. Cell. Infect. Microbiol. 2013, 3, 43. [CrossRef]

114. Hourcade, D.E.; Akk, A.M.; Mitchell, L.M.; Zhou, H.-F.; Hauhart, R.; Pham, C.T. Anti-complement activity of the Ixodes scapularis salivary protein Salp20. Mol. Immunol. 2016, 69, 62-69. [CrossRef]

115. Dulipati, V.; Meri, S.; Panelius, J. Complement evasion strategies of Borrelia burgdorferi sensu lato. FEBS Lett. 2020, 594, 2645-2656. [CrossRef]

116. Skare, J.T.; Garcia, B.L. Complement Evasion by Lyme Disease Spirochetes. Trends Microbiol. 2020, 28, 889-899. [CrossRef]

117. Lin, Y.-P.; Frye, A.M.; Nowak, T.A.; Kraiczy, P. New Insights Into CRASP-Mediated Complement Evasion in the Lyme Disease Enzootic Cycle. Front. Cell. Infect. Microbiol. 2020, 10, 1. [CrossRef]

118. Salo, J.; Jaatinen, A.; Söderström, M.; Viljanen, M.K.; Hytönen, J. Decorin Binding Proteins of Borrelia burgdorferi Promote Arthritis Development and Joint Specific Post-Treatment DNA Persistence in Mice. PLoS ONE 2015, 10, e0121512. [CrossRef] 
119. Liang, F.T.; Brown, E.L.; Wang, T.; Iozzo, R.V.; Fikrig, E. Protective Niche for Borrelia burgdorferi to Evade Humoral Immunity. Am. J. Pathol. 2004, 165, 977-985. [CrossRef]

120. Garin, J.; Diez, R.; Kieffer, S.; Dermine, J.F.; Duclos, S.; Gagnon, E.; Sadoul, R.; Rondeau, C.; Desjardins, M. The phagosome proteome: Insight into phagosome functions. J. Cell Biol. 2001, 152, 165-180. [CrossRef] 